Research Article

\title{
Comparison of 3DVar and EnSRF Data Assimilation Using Radar Observations for the Analysis and Prediction of an MCS
}

\author{
Shibo Gao $(1)$ and Jinzhong Min (iD \\ Key Laboratory of Meteorological Disaster, Ministry of Education (KLME), Joint International Research Laboratory of Climate \\ and Environment Change (ILCEC), Collaborative Innovation Center on Forecast and Evaluation of Meteorological Disaster \\ (CICFEMD), Nanjing University of Information Science and Technology, Nanjing 210044, China
}

Correspondence should be addressed to Jinzhong Min; minjz@nuist.edu.cn

Received 22 September 2017; Revised 8 March 2018; Accepted 19 March 2018; Published 20 May 2018

Academic Editor: Stefano Federico

Copyright (C) 2018 Shibo Gao and Jinzhong Min. This is an open access article distributed under the Creative Commons Attribution License, which permits unrestricted use, distribution, and reproduction in any medium, provided the original work is properly cited.

\begin{abstract}
Using radar observations, the performances of the ensemble square root filter (EnSRF) and an indirect three-dimensional variational (3DVar) data assimilation method were compared for a mesoscale convective system (MCS) that occurred in the Front Range of the Rocky Mountains, Colorado (USA). The results showed that the root mean square innovations (RMSIs) of EnSRF were lower than 3DVar for radar reflectivity and radial velocity and that the spread of EnSRF was generally consistent with its RMSIs. EnSRF substantially improved the analysis of the MCS compared with an experiment without radar data assimilation, and it produced a slight but noticeable improvement over 3DVar in terms of both coverage and intensity. Forecast results initiated from the final analysis revealed that EnSRF generally produced the best prediction of the MCS, with improved quantitative reflectivity and precipitation forecast skills. EnSRF also demonstrated better performance than 3DVar in the prediction of neighborhood probability for reflectivity at thresholds of 20 and $35 \mathrm{dBZ}$, which better matched the observed radar reflectivity in terms of both shape and extension. Additionally, the humidity, temperature, and wind fields were also improved by EnSRF; the largest error reduction was found in the water vapor field near the surface and at upper levels.
\end{abstract}

\section{Introduction}

Mesoscale convective systems (MCSs) are severe convective storms that can cause injury and damage property. However, accurate prediction of MCSs remains a challenge because of their rapid development and evolution. Doppler radars are platforms capable of observing MCS structure with high resolution and frequency, and such observations have been used for convective-scale data assimilation to improve the initial conditions of numerical weather prediction (NWP) models.

The three-dimensional variational (3DVar) data assimilation (DA) system, which includes mass continuity equations and other model equations as weak constraints, is efficient for storm-scale DA. Xiao et al. [1, 2] developed a Weather Research and Forecasting DA (WRFDA) 3DVar system to assimilate radial velocity and radar reflectivity by considering the total water vapor mixing ratio as a control variable, which improved quantitative precipitation forecasts for a hurricane. However, their system is limited to warm rain microphysics. Gao and Stensrud [3] used the background temperature to classify hydrometers to include ice and snow microphysics. Wang et al. [4] developed an approach for indirect radar reflectivity assimilation that assimilates retrieved rainwater and in-cloud water vapor estimated from radar reflectivity. An advantage of this new approach is that it avoids linearization errors attributable to the nonlinear relationship between reflectivity and microphysical variables. It has been used in several recent studies and it has demonstrated capability in improving short-term forecasts of convective storms [5-7]. However, it cannot overcome the inherent weakness of the 3DVar method that results from the neglect of the flow-dependent nature of the background error covariance (BEC). This problem is most severe in storm-scale 


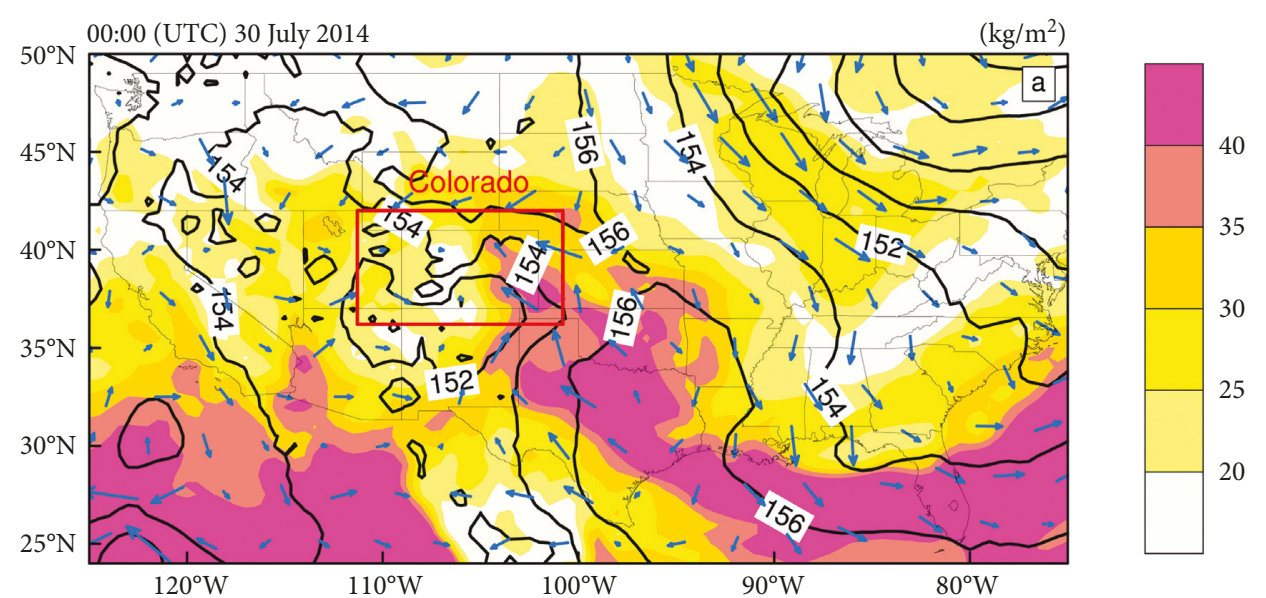

(a)

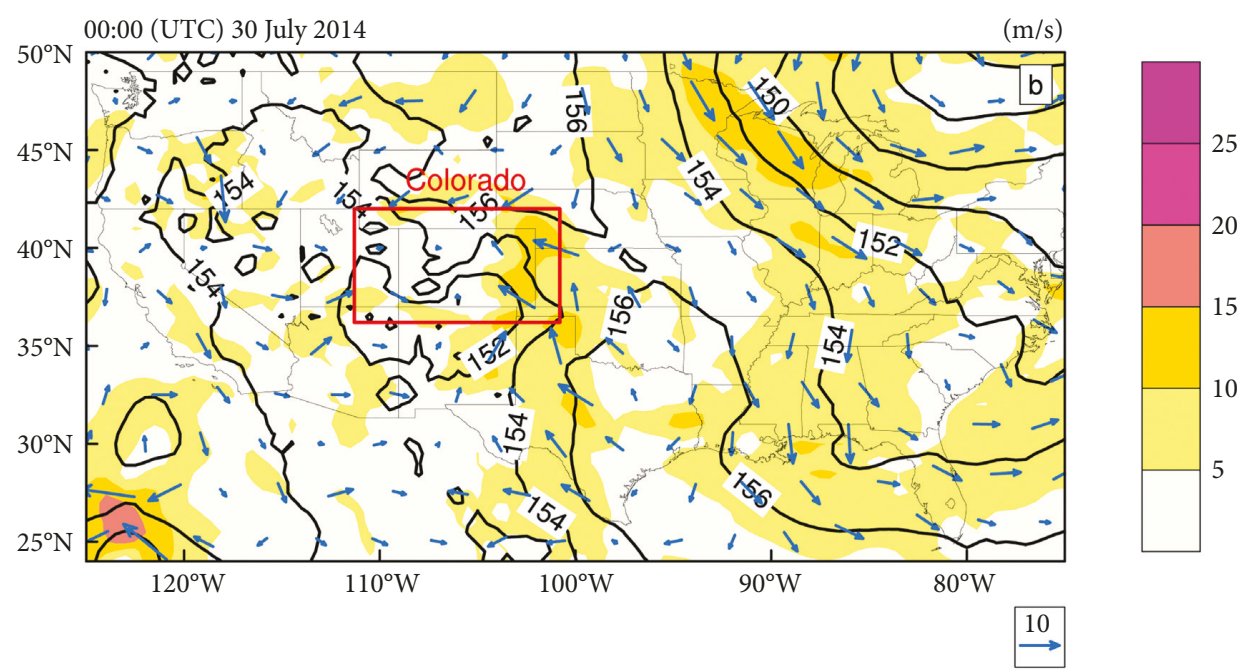

(b)

FIGURE 1: Environmental variables based on Global Forecast System (GFS) analysis data at 850 hPa at 0000 UTC 30 July 2014 : geopotential height (black solid lines, unit: dagpm), wind vectors (blue vector, unit: $\mathrm{m} \cdot \mathrm{s}^{-1}$ ). (a) Column-integrated precipitable water (shaded, unit: $\mathrm{kg} \cdot \mathrm{m}^{-2}$ ); (b) wind speed (shaded, unit: $\mathrm{m} \cdot \mathrm{s}^{-1}$ ).

DA because few state variables are observed directly and large-scale balance relationships are invalid.

Another advanced DA method for convective-scale NWP is the ensemble Kalman filter (EnKF), which estimates BEC using an ensemble of forecasts. EnKF is able to evolve the BEC dynamically throughout multiple assimilation cycles. Cross covariance produced by EnKF is especially important for convective-scale DA because state variables that are not observed directly can be updated. Snyder and Zhang [8] and Zhang et al. [9] first demonstrated the capability of EnKF for convective-scale DA using radar radial winds acquired during observing system simulation experiments. Subsequent studies by Xue et al. $[10,11]$ showed the performance of EnKF could be improved further when radar reflectivity was also assimilated into a compressible model with complex ice microphysics. The application of EnKF for assimilating real radar data has also produced successful results for several convective cases [12, 13]. It has been found that EnKF can handle complex and highly nonlinear processes involved in DA, which makes it attractive for convective-scale DA [14-16].

Several studies have demonstrated that the performance of EnKF was better than 3DVar in global- to mesoscale DA [17-20]. Whitaker et al. [18] found that EnKF produced an improvement in analysis and forecasting relative to 3DVar when using the National Centers for Environmental Prediction (NCEP) Global DA system, especially in data-sparse regions. Meng and Zhang [20] showed that EnKF generally outperformed 3DVar by assimilating observations from either individual or multiple data platforms (e.g., soundings, and surface and wind profilers) for a mesoscale convective vortex event. However, few studies have compared the performances of $3 \mathrm{DV}$ ar and EnKF for real convective storms. Johnson et al. [21] compared EnKF and 3DVar at multiple scales, and they found that the method of radar assimilation using EnKF could maintain the storm features throughout the entire forecast period, whereas a 3DVar forecast produced some deficits after the first hour. 


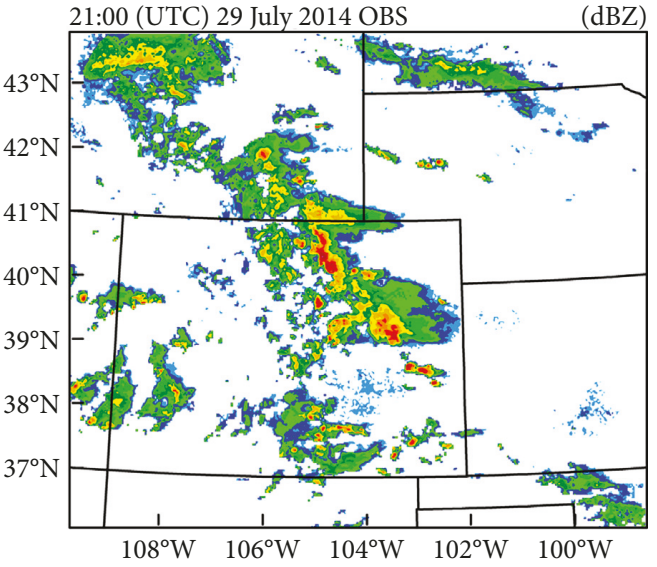

(a)

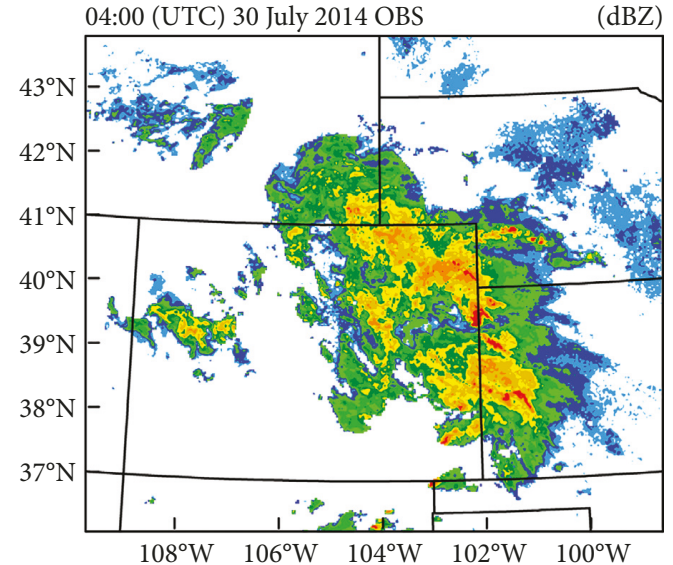

(c)

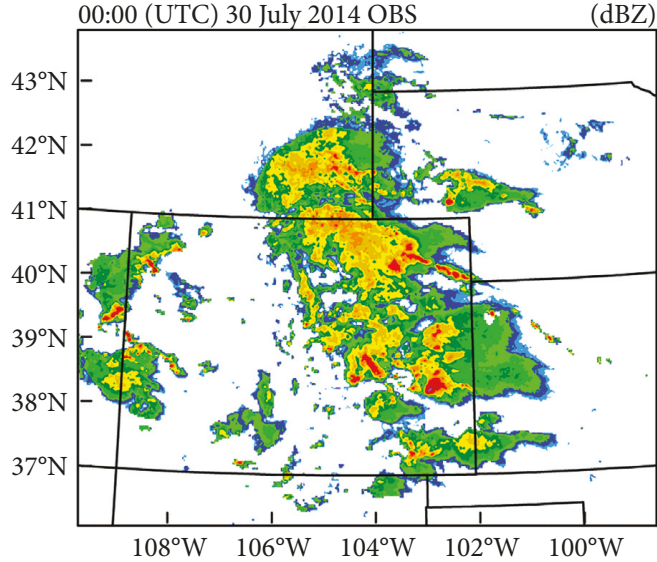

(b)

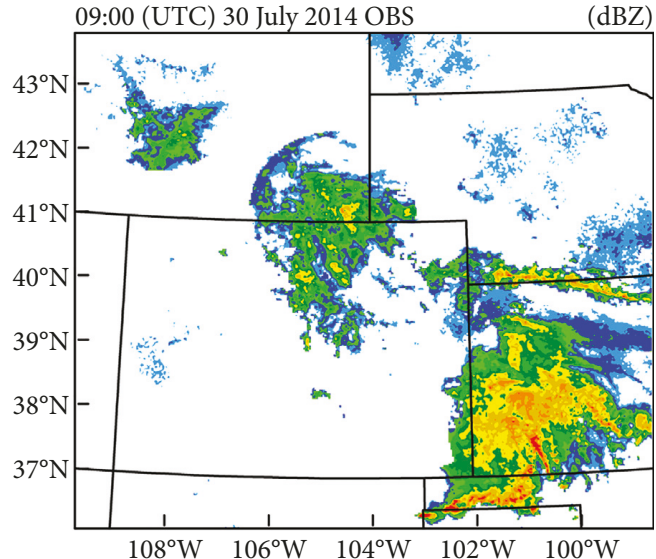

(d)

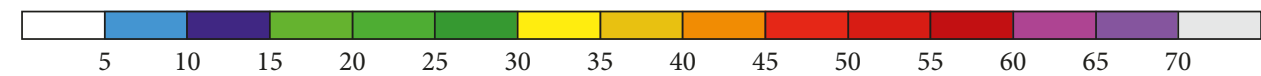

FIGURE 2: Observations of composite radar reflectivity (unit: dBZ) showing evolution of the mesoscale convective system (MCS) at 2100 UTC 29 July 2014 (a), 0000 UTC 30 July 2014 (b), 0400 UTC 30 July 2014 (c), and 0900 UTC 30 July 2014 (d).

In the context of convective-scale DA, the present study systematically compared the ensemble square root filter (EnSRF) and a newly developed indirect 3DVar method. The indirect 3DVar method used was that proposed by Wang et al. [4], which includes a procedure to assimilate an estimated in-cloud humidity field. A case study was conducted to investigate the impact of using different radar DA techniques on both the analysis and the subsequent prediction of an MCS that occurred over the Front Range of the Rocky Mountains in Colorado (USA) on 30 July 2014, which demonstrated the promising results of EnSRF over 3DVar in MCS analysis and forecasting. The remainder of this paper is arranged as follows. Section 2 presents the indirect 3DVar and EnSRF radar DA methods. The case description and the experimental setups are outlined in Section 3. Section 4 describes the analysis and forecast results, and the summary is presented in Section 5.

\section{Method}

2.1. WRFDA 3DVar Indirect Radar Data Assimilation Method. The indirect reflectivity assimilation approach of the WRFDA 3DVar system for convective-scale radar DA [4] was used in this study. The cost function in an updated system can be expressed as follows:

$$
J=J_{\mathrm{b}}+J_{\mathrm{o}} \text {, }
$$

where the subscript $b$ represents the background and the subscript o represents the observation terms. To avoid the linearization error of the reflectivity-rainwater equation, two additional observation terms, corresponding to the rainwater mixing ratio and in-cloud water vapor (both estimated from reflectivity), are added in the cost function. Here, we extended the system by including snow and graupel in $J_{\mathrm{b}}$ and $J_{\mathrm{o}}$, where

$$
\begin{aligned}
J_{\mathrm{qm}}= & \frac{1}{2}\left(\mathbf{q}_{\mathrm{m}}-\mathbf{q}_{\mathrm{m}}^{\mathrm{b}}\right)^{T} \mathbf{B}_{\mathrm{qm}}^{-\mathbf{1}}\left(\mathbf{q}_{\mathrm{m}}-\mathbf{q}_{\mathrm{m}}^{\mathrm{b}}\right) \\
& +\frac{1}{2}\left(\mathbf{q}_{\mathrm{m}}-\mathbf{q}_{\mathrm{m}}^{\mathrm{o}}\right)^{T} \mathbf{R}_{\mathrm{qm}}^{-1}\left(\mathbf{q}_{\mathrm{m}}-\mathbf{q}_{\mathrm{m}}^{\mathrm{o}}\right), \\
J_{\mathrm{qv}}= & \frac{1}{2}\left(\mathbf{q}_{\mathrm{v}}-\mathbf{q}_{\mathrm{v}}^{\mathrm{o}}\right)^{T} \mathbf{R}_{\mathrm{qv}}^{-1}\left(\mathbf{q}_{\mathrm{v}}-\mathbf{q}_{\mathrm{v}}^{\mathrm{o}}\right) .
\end{aligned}
$$




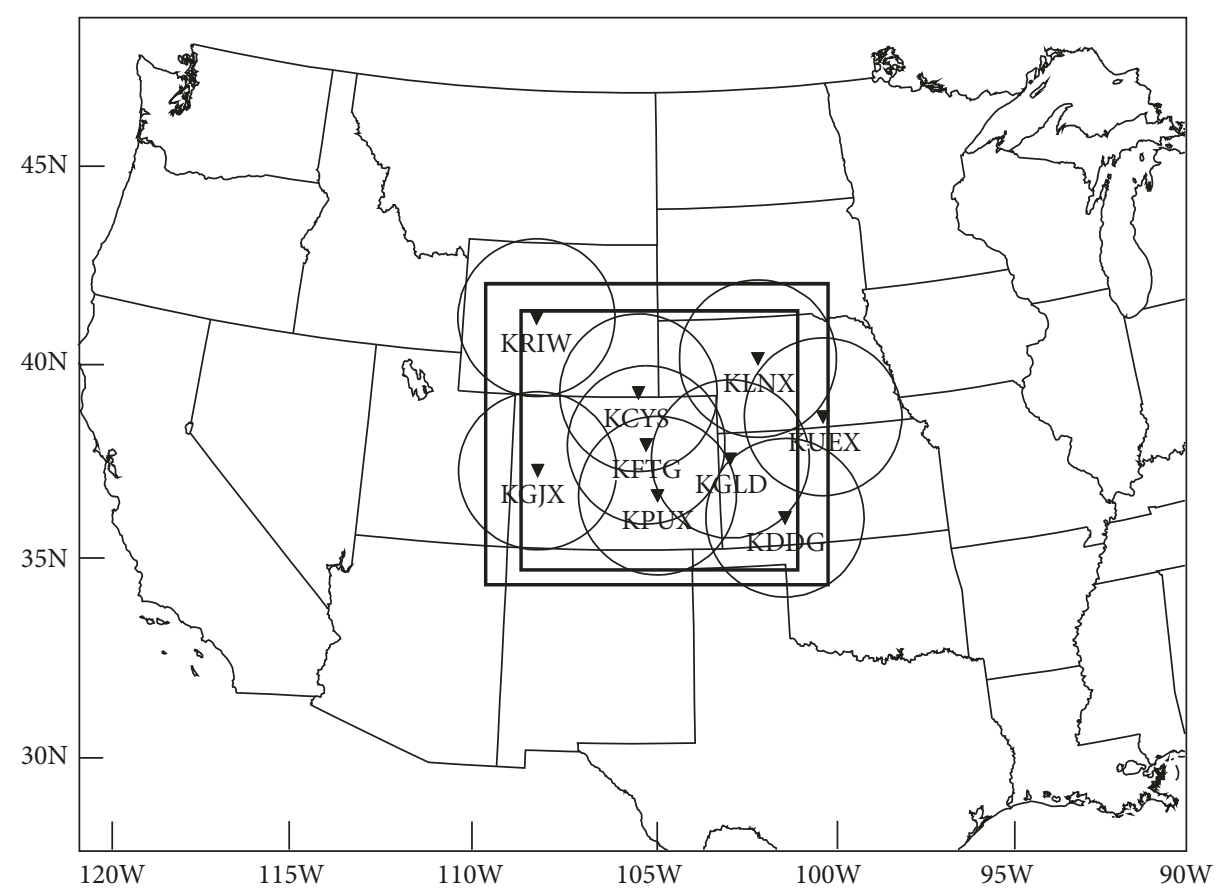

FIgURE 3: The three model domains and locations of the nine radar stations (inverted black triangles): KRIW (Riverton, WY), KLNX (North Platte, NE), KCYS (Cheyenne, WY), KUEX (Hastings, NE), KGJX (Grand Junction, CO), KFTG (Denver, CO), KGLD (Goodland, KS), KPUX (Pueblo, CO), and KDDC (Dodge City, KS). Maximum ranges of radars are shown by circles.

TABLE 1: List of experiments.

\begin{tabular}{lc}
\hline Experiments & Description \\
\hline NoDA & $\begin{array}{c}\text { No data assimilation } \\
\text { 3DVar }\end{array}$ \\
EnSRF & $\begin{array}{c}\text { EnSRF assimilating both radial velocity } \\
\text { and reflectivity } \\
\text { and reflectivity }\end{array}$ \\
\hline
\end{tabular}

Here, $\mathbf{q}_{\mathrm{m}}$ represents the hydrometeor mixing ratios (rainwater, snow, graupel-hail) of the atmospheric state, $\mathbf{q}_{\mathrm{m}}^{b}$ are their background first guesses, $\mathbf{q}_{\mathrm{m}}^{\mathrm{o}}$ are their observations retrieved from radar reflectivity, and $\mathbf{R}_{\mathrm{qm}}$ and $\mathbf{B}_{\mathrm{qm}}$ are their related observational variances and background error matrix, respectively; $\mathbf{q}_{\mathrm{v}}, \mathbf{q}_{\mathrm{v}}^{\mathrm{o}}$, and $\mathbf{R}_{\mathrm{qv}}$ are the water vapor mixing ratios, their observations retrieved from radar reflectivity, and their related observational variances, respectively. The radar radial velocity assimilation followed the procedure in Xiao et al. [1]. In the assimilation of radial velocity, the operator includes the rainwater terminal velocity, and the terminal velocity can be calculated according to the rainwater mixing ratio.

2.2. EnSRF. For the standard EnKF, the update equations can be formulated as follows:

$$
\begin{aligned}
x_{i}^{\mathrm{b}}(t) & =\mathbf{M} x_{i}^{\mathrm{a}}(t-1), \\
x_{i}^{\mathrm{a}} & =x_{i}^{\mathrm{b}}+\mathbf{K}\left(y_{i}^{\mathrm{o}}-H x_{i}^{\mathrm{b}}\right),
\end{aligned}
$$

$$
\begin{aligned}
\mathbf{K} & =\mathbf{P}^{\mathrm{b}} \mathbf{H}^{\mathrm{T}}\left(\mathbf{H P}^{\mathrm{b}} \mathbf{H}^{\mathrm{T}}+\mathbf{R}\right)^{-\mathbf{1}} \\
\mathbf{H} \mathbf{P}^{\mathrm{b}} \mathbf{H}^{\mathrm{T}} & \cong \frac{1}{N-1} \sum_{i}^{N}\left[H\left(x_{i}^{\mathrm{b}}\right)-\overline{H\left(x^{\mathrm{b}}\right)}\right]\left[H\left(x_{i}^{\mathrm{b}}\right)-\overline{H\left(x^{\mathrm{b}}\right)}\right]^{T}, \\
\mathbf{P}^{\mathrm{b}} \mathbf{H}^{\mathrm{T}} & \cong \frac{1}{N-1} \sum_{i}^{N}\left(x_{i}^{\mathrm{b}}-\overline{x^{\mathrm{b}}}\right)\left[H\left(x_{i}^{\mathrm{b}}\right)-\overline{H\left(x^{\mathrm{b}}\right)}\right]^{T}
\end{aligned}
$$

where $x$ is the ensemble state vector, $\mathbf{K}$ is the Kalman gain matrix, $H$ is the observation operator that projects state variables to observed quantities, and $\mathbf{H}$ is the linearized version of $H$. The covariance matrices for the observation and background errors are $\mathbf{R}$ and $\mathbf{P}$, respectively, $\mathbf{M}$ denotes the NWP model, and $t$ is the current analysis time. Here, subscript $i$ denotes the ensemble member order ranging from 1 to $N$, and $N$ is the ensemble size. The superscripts b, a, and o denote the background, analysis, and observation, respectively, and the overbar ${ }^{-}$represents an ensemble mean.

To avoid introducing additional sampling errors to the ensemble, we used the EnSRF algorithm [22], which replaces (4) with the following equation:

$$
\begin{aligned}
\bar{x}^{\mathrm{a}} & =\bar{x}^{\mathrm{b}}+\mathbf{K}\left(y^{\mathrm{o}}-H\left(\bar{x}^{\mathrm{b}}\right)\right), \\
x_{i}^{\prime \mathrm{a}} & =\beta(\mathbf{I}-\alpha \mathbf{K H}) x_{i}^{\prime \mathrm{b}}, \\
\alpha & =\left[1+\sqrt{\mathbf{R}\left(\mathbf{H} \mathbf{P}^{\mathrm{b}} \mathbf{H}^{\mathrm{T}}+\mathbf{R}\right)^{-1}}\right]^{-1},
\end{aligned}
$$

where $\alpha$ is a factor in the square root algorithm and $\beta$ is the covariance inflation factor [23], which is used to deal with sampling and model errors. I is an identity matrix. The 


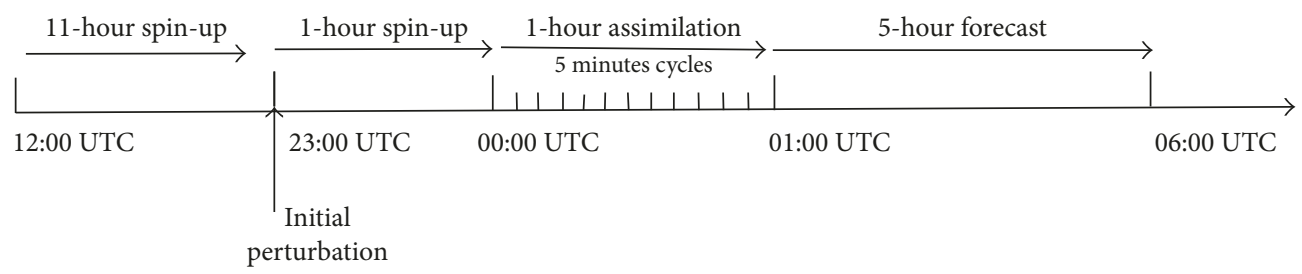

FIGURE 4: Diagram of initial spin-up forecast, data assimilation cycles, and subsequent forecast for the EnSRF experiment.

prime symbol $\left({ }^{\prime}\right)$ in the equations represents the perturbation of the ensemble members.

\section{Case Description and Experiment Design}

An MCS that occurred over the Front Range of the Rocky Mountains in Colorado (USA) on 29-30 July 2014 was selected to investigate the differences between 3DVar and EnKF in storm-scale DA. The MCS originated in an environment associated with a cold front and a cyclone. The lowlevel precipitable water and wind field at $850 \mathrm{hPa} 0000$ UTC 30 July 2014 are shown in Figure 1. Convergence between the northerly cold dry air and southerly warm moist air caused intense convection over northern Colorado, where the precipitable water was $>40 \mathrm{~kg} \cdot \mathrm{m}^{-2}$ (Figure $1(\mathrm{a})$ ) and the maximum wind speed was up to $15 \mathrm{~m} \cdot \mathrm{s}^{-1}$ (Figure $1(\mathrm{~b})$ ). The system persisted for $13 \mathrm{~h}$ and it caused heavy rain, strong winds, and frequent lightning.

Figure 2 shows the evolution of this MCS in terms of radar composite reflectivity at different times. At 2100 UTC 29 July 2014 (Figure 2(a)), convective cells had become organized into a convective line over eastern Colorado, with maximum reflectivity of $55 \mathrm{dBZ}$. There were also some isolated convective cells in southern Wyoming and western Colorado. At 0000 UTC 30 July (Figure 2(b)), the MCS developed and became substantial. The northern part developed rapidly with a large area of reflectivity of 30-45 dBZ. At 0400 UTC 30 July (Figure 2(c)), the MCS was in the mature stage and its southern part became larger and intensified further. During the southeastward movement, some isolated convective cells became incorporated into the moving convective system. By 0900 UTC 30 July (Figure 2(d)), the area of intense radar echoes had contracted, weakened, and moved into Kansas.

The Advanced Research WRF (ARW) version 3.9 was adopted as the forecast model used in this study. The model domain was set using two-way nesting between three nested grids, which had horizontal grid spacings of 15,3 , and $1 \mathrm{~km}$ that generated $211 \times 161,321 \times 281$, and $802 \times 751$ horizontal grid points, respectively. All domains had 51 vertical grid levels from the surface up to $50 \mathrm{hPa}$.

The model domains and the locations of the radar stations are shown in Figure 3. The Kain-Fritsch (KF) cumulus parameterization scheme [24] was used only in domain 1. Other model physics schemes adopted included the Thompson microphysics scheme [25], Mellor-YamadaJanjić (MYJ) planetary boundary layer model [26], Noah land surface model [27], and Rapid Radiative Transfer
Model for GCMs (RRTMG) for longwave and shortwave radiation [28].

As shown in Figure 3, nine high-resolution radars of the Weather Surveillance Radars-1988 Doppler network were used in the DA. Quality control that included despeckling, removal of ground clutter for reflectivity, and velocity de-aliasing (unfolding) [29] was conducted before the radar data were assimilated in the $3 \mathrm{~km}$ domain. For the overlapping radar observations, a data location check is conducted in both 3DVar and EnSRF DA systems to avoid counting the same radar observations. When the distance between radar data and radar site is longer than another data, the radar observation is not assimilated. Observations used for rainfall verification were quantitative precipitation estimates from the Multi-Radar/Multi-Sensor System developed by the National Severe Storms Laboratory [30].

Three experiments comprising NoDA, 3DVar, and EnSRF (Table 1) were designed to examine the impact of different radar DA methods on both the analysis and the prediction of the MCS. The NoDA experiment did not assimilate any data, and the initial and lateral boundary conditions were obtained from the $0.5^{\circ} \times 0.5^{\circ}$ NCEP operational Global Forecast System (GFS). For the 3DVar experiment, a $12 \mathrm{~h}$ spin-up forecast was performed starting from 1200 UTC 29 July 2014 . The radar data were assimilated every $5 \mathrm{~min}$ for $1 \mathrm{~h}$ in the $3 \mathrm{~km}$ domain, and the $\mathrm{Na}$ tional Meteorological Center (NMC) method [31] was used to estimate background error covariance for assimilation of radar observations. Then, a $5 \mathrm{~h}$ deterministic forecast was conducted from 0100 to 0600 UTC 30 July 2014 in the $1 \mathrm{~km}$ domain.

For the EnSRF experiment, as shown in Figure 4, 40 members were generated using the random-CV [32] method after an $11 \mathrm{~h}$ spin-up forecast initialized from the NCEP GFS analysis at 1200 UTC 29 July 2014. The amplitudes of the perturbations for the horizontal wind $(u, v)$, potential temperature $(\theta)$, and water vapor mixing ratio $\left(q_{\mathrm{v}}\right)$ were approximately $2 \mathrm{~m} \cdot \mathrm{s}^{-1}, 2 \mathrm{~K}$, and $1 \mathrm{~g} \cdot \mathrm{kg}^{-1}$, respectively. Then, a $1 \mathrm{~h}$ ensemble forecast was conducted to develop the BEC for sampling the mesoscale environmental uncertainties. Radar data were assimilated every $5 \mathrm{~min}$ until 0100 UTC 30 July 2014 in the $3 \mathrm{~km}$ domain. The horizontal and vertical covariance localization radii were 12 and $4 \mathrm{~km}$, respectively. A multiplicative covariance inflation following Xue et al. [11] with a factor of 1.25 was used to help maintain the ensemble spread. Additive noise [33] was also added to the analysis members with standard deviations of $0.5 \mathrm{~m} \cdot \mathrm{s}^{-1}$ for $u$ and $v, 0.5 \mathrm{~K}$ for $\theta$, and $0.1 \mathrm{~g} \cdot \mathrm{kg}^{-1}$ for $q_{\mathrm{v}}$. 


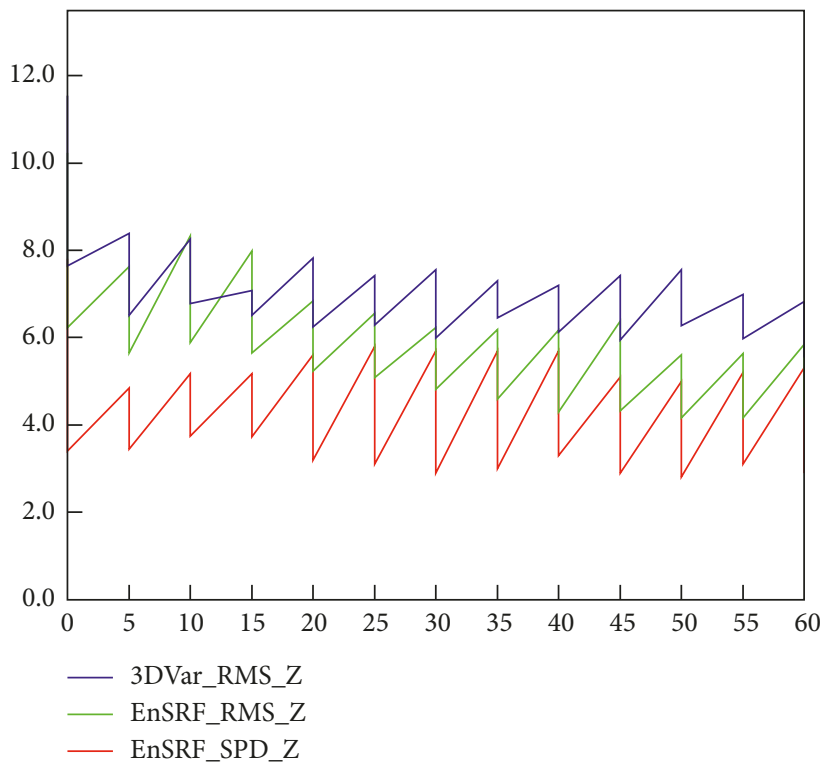

(a)

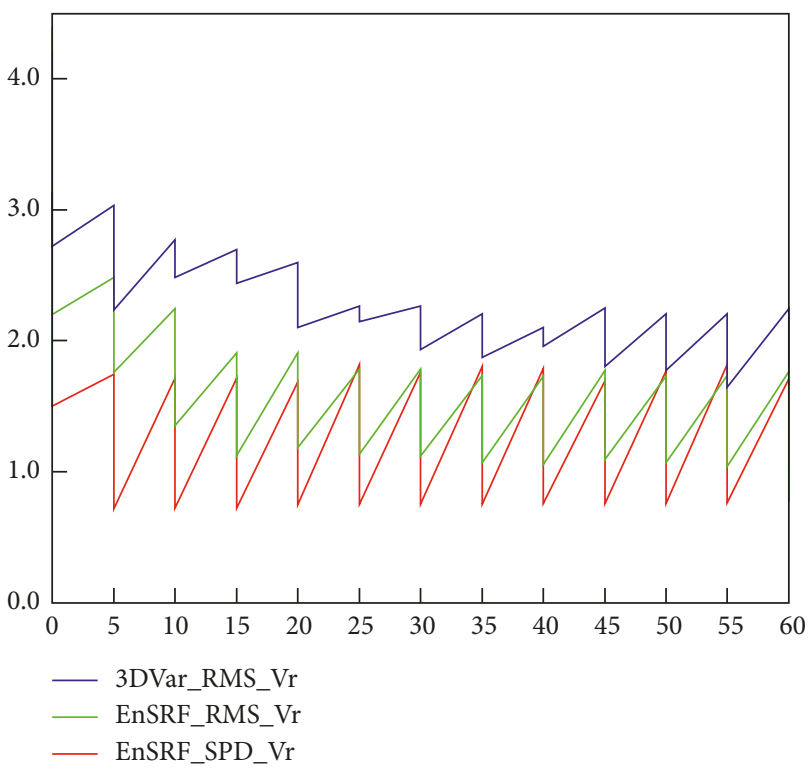

(b)

FIGURE 5: Root mean square innovations (RMSIs) and ensemble spreads for the experiments of 3DVar and EnSRF for reflectivity (unit: dBZ) (a) and radial velocity (unit: $\mathrm{m} \cdot \mathrm{s}^{-1}$ ) (b) calculated against the KFTG (Denver, CO) radar during the assimilation period.

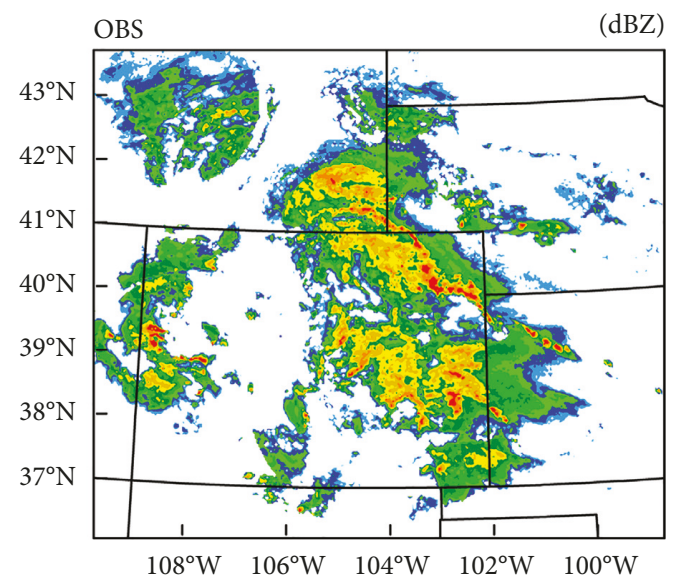

(a)

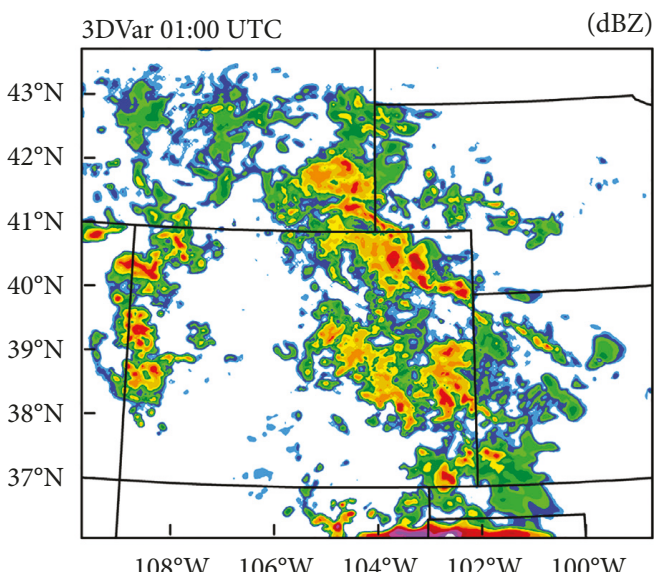

(c)

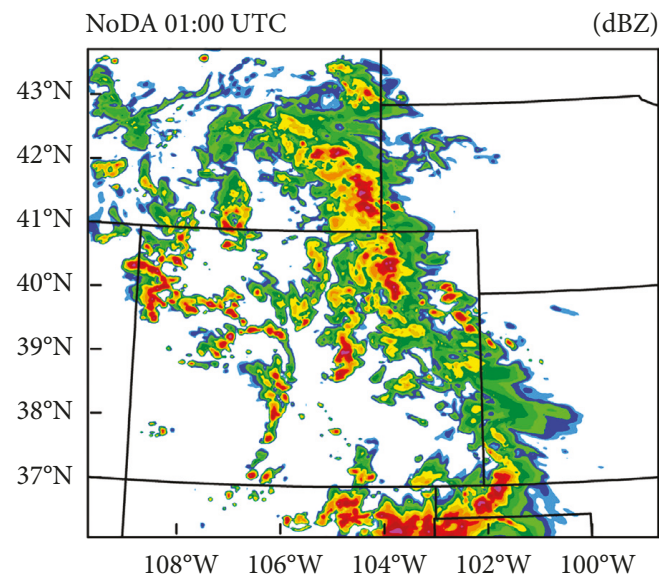

(b)

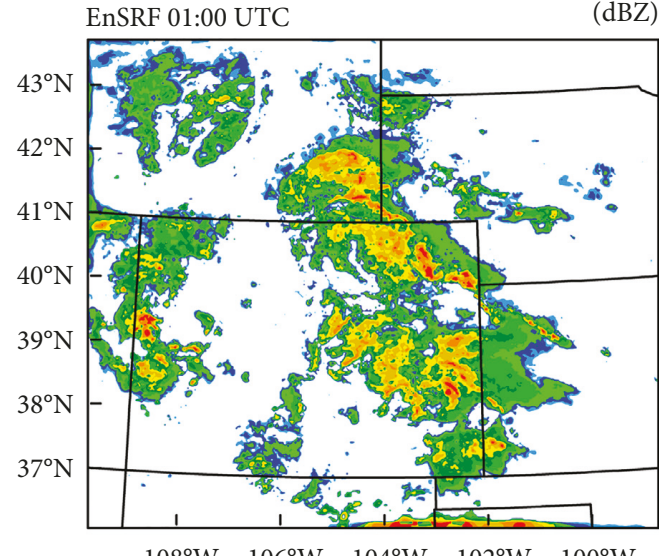

(d)

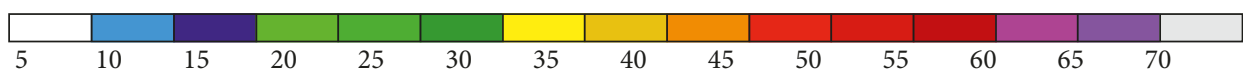

Figure 6: Composite radar reflectivity (unit: dBZ) of the mesoscale convective system (MCS) observation (OBS) (a) and results from the NoDA (b), 3DVar (c), and EnSRF (d) experiments at 0100 UTC 30 July 2014. 


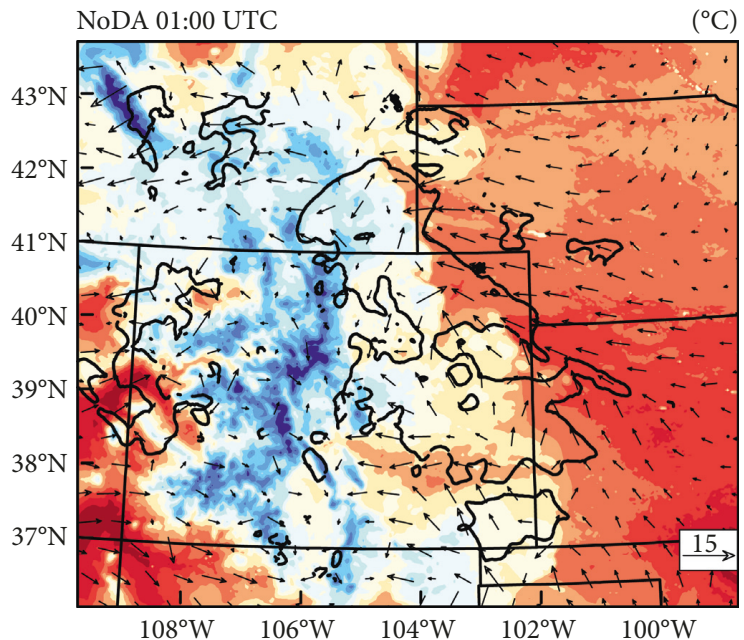

(a)

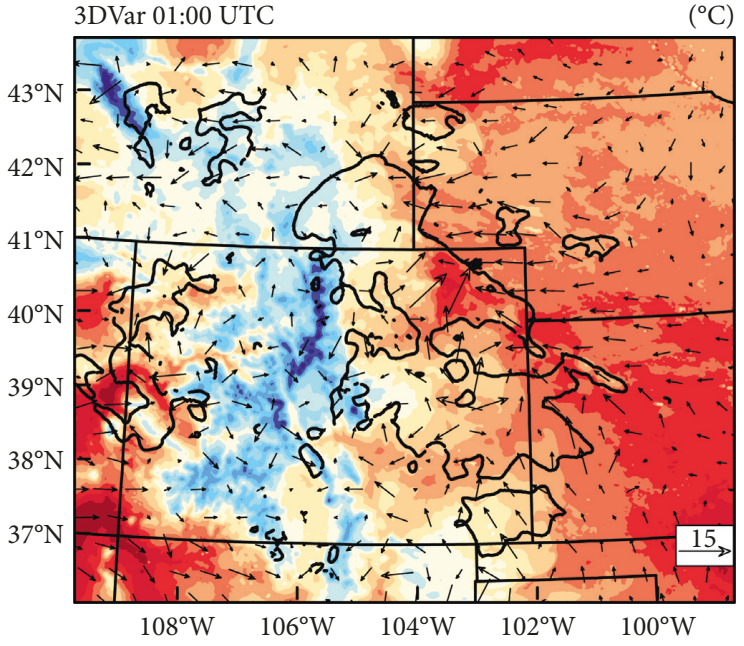

(b)
EnSRF 01:00 UTC

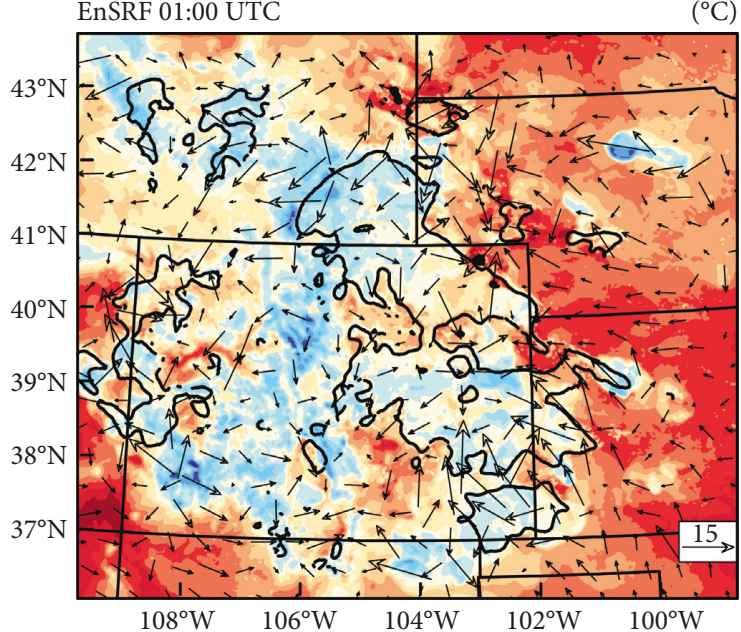

(c)

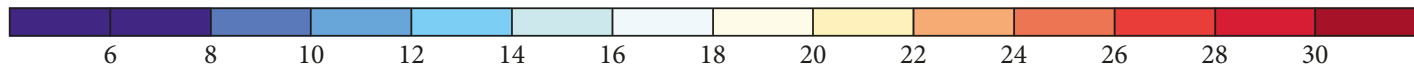

Figure 7: Surface temperature (unit: ${ }^{\circ} \mathrm{C}$ ) and wind (unit: $\mathrm{m} \cdot \mathrm{s}^{-1}$ ) from the NoDA (a), 3DVar (b), and EnSRF (c) experiments at 0100 UTC 30 July 2014. Solid black lines represent contours of observed reflectivity $>20 \mathrm{dBZ}$.

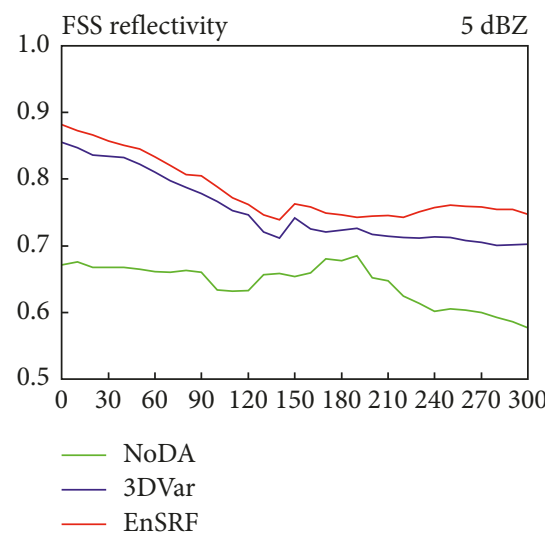

(a)

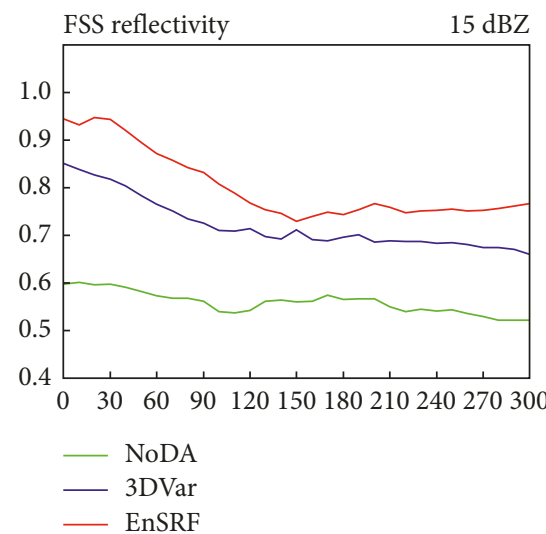

(b)

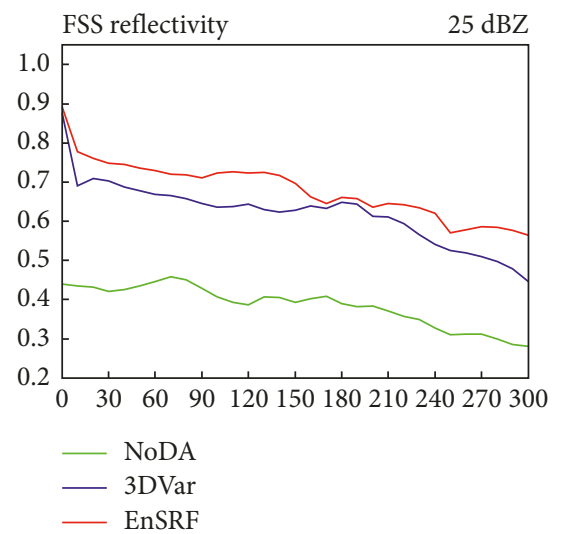

(c)

FIgURE 8: Continued. 


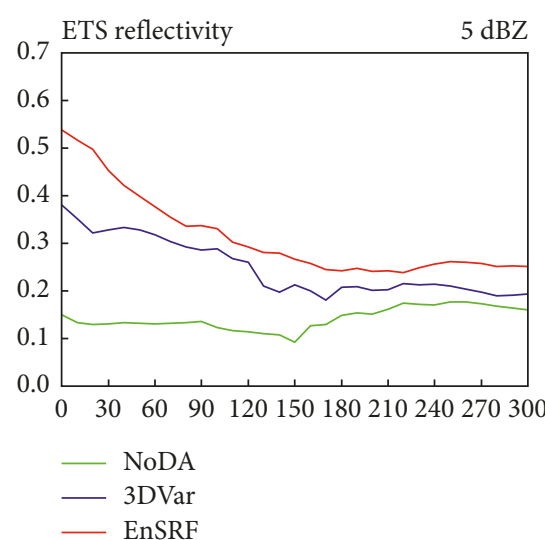

(d)

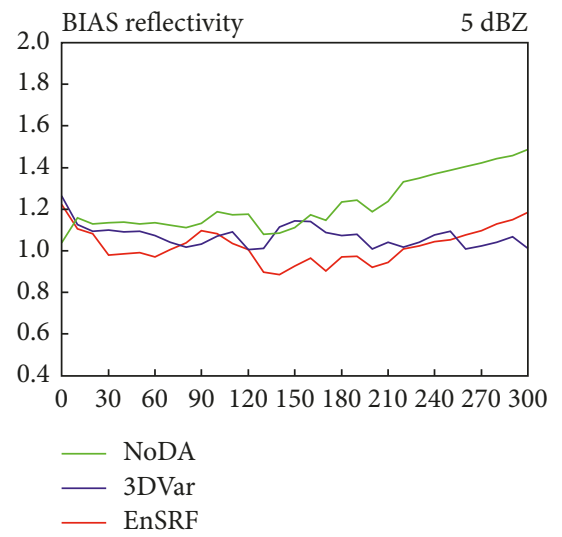

(g)

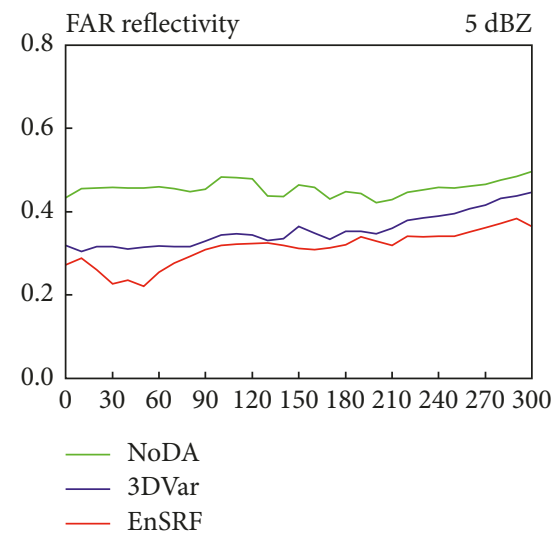

(j)

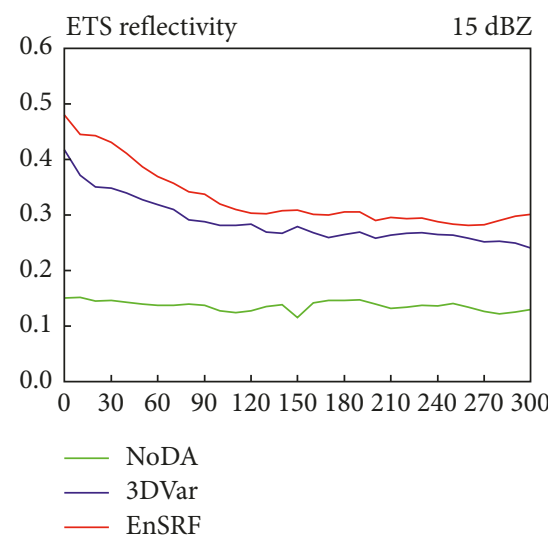

(e)

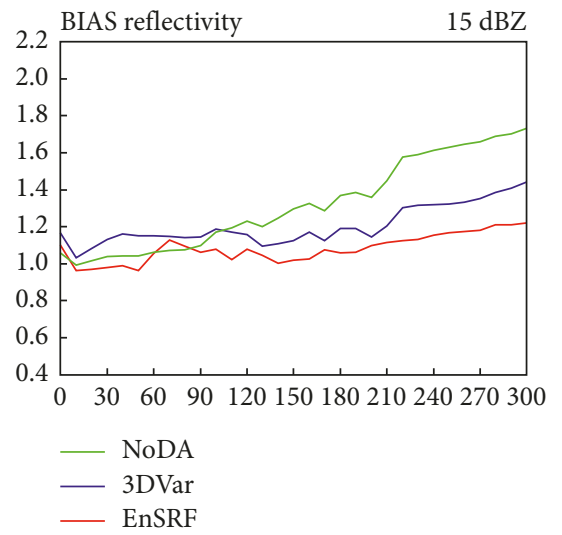

(h)

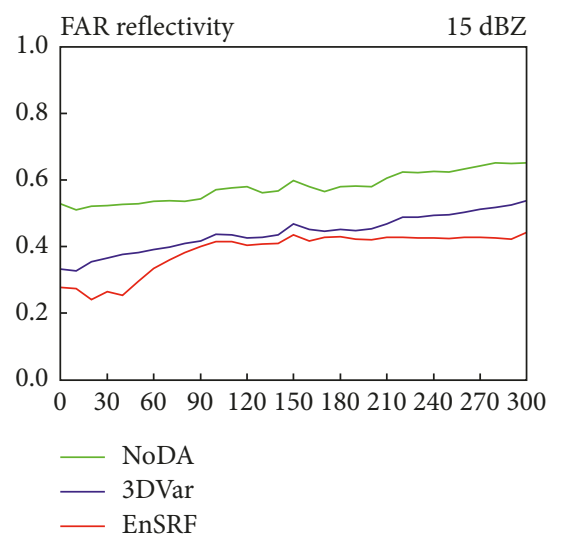

(k)

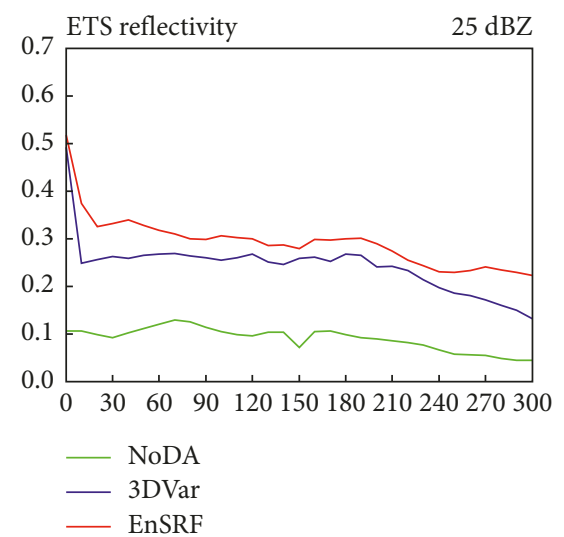

(f)

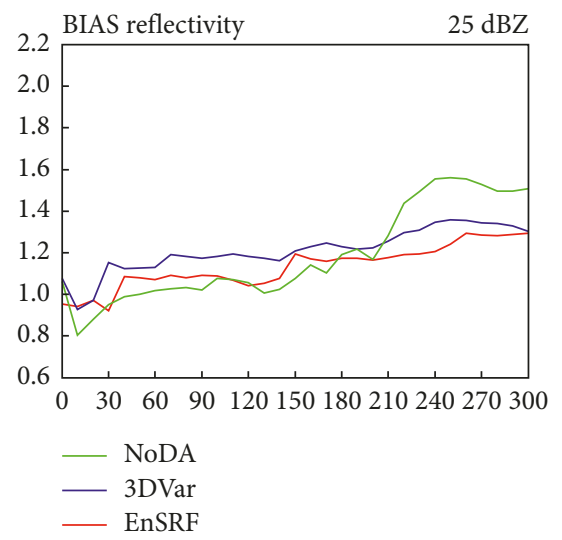

(i)

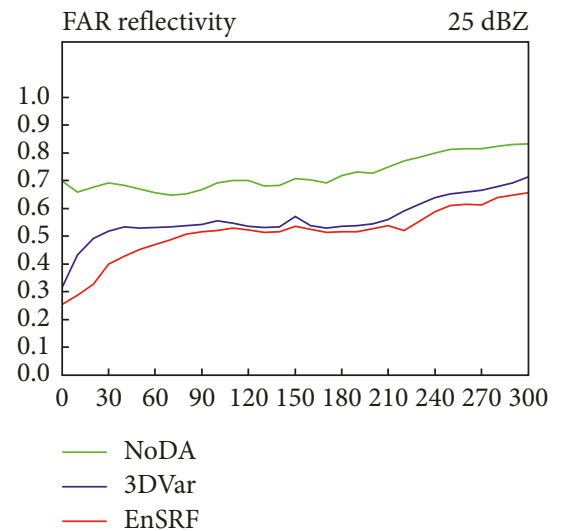

(l)

FIGURE 8: Fractions skill score (FSS) (a-c), equitable threat score (ETS) (d-f), BIAS (g-i), and false alarm ratio (FAR) (j-l) for reflectivity thresholds of 5 (a, d, g, j), 15 (b, e, h, k), and $25 \mathrm{dBZ}(\mathrm{c}, \mathrm{f}, \mathrm{i}, \mathrm{l})$ for the three experiments NoDA (green curve), 3DVar (blue curve), and EnSRF (red curve).

Finally, $5 \mathrm{~h}$ deterministic and ensemble forecasts were produced at 0100 UTC 30 July 2014 in the $1 \mathrm{~km}$ domain from the interpolated ensemble mean and the analysis members, respectively.

\section{Results}

4.1. Analysis Result. To evaluate the performances of the 3DVar and the EnSRF analyses quantitatively, the root mean square innovations (RMSIs) and the ensemble spread were calculated for radar reflectivity and radial velocity during the $1 \mathrm{~h}$ assimilation period (Figure 5). The RMSIs provide a measure of the overall fit of the model state to the observations, and the ensemble spread can be used to examine analysis uncertainty. The calculation was limited to regions where reflectivity was $>15 \mathrm{dBZ}$. Generally, the RMSIs of radar reflectivity and radial velocity for both 3DVar and EnSRF tended to decrease with time. EnSRF 


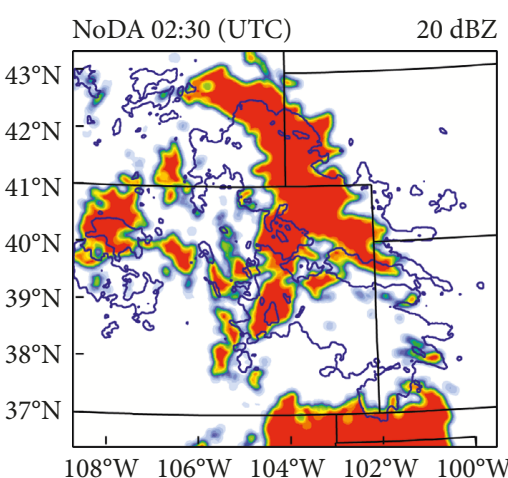

(a)

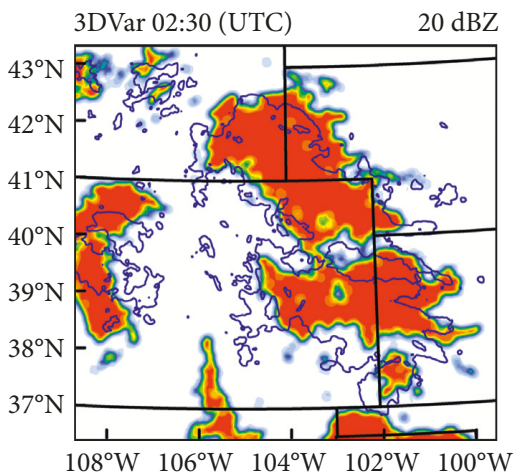

(d)

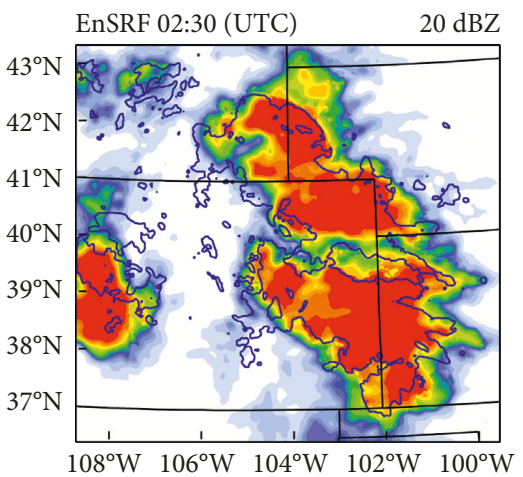

(g)

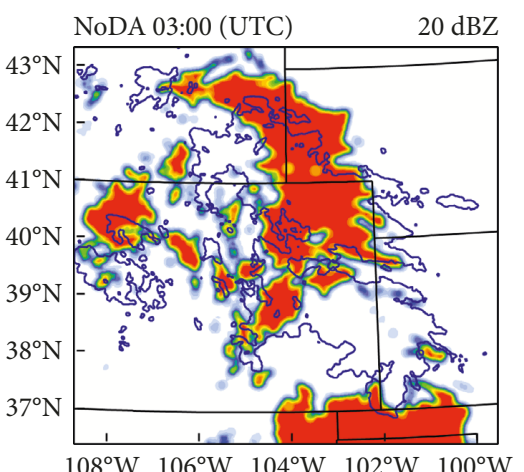

(b)

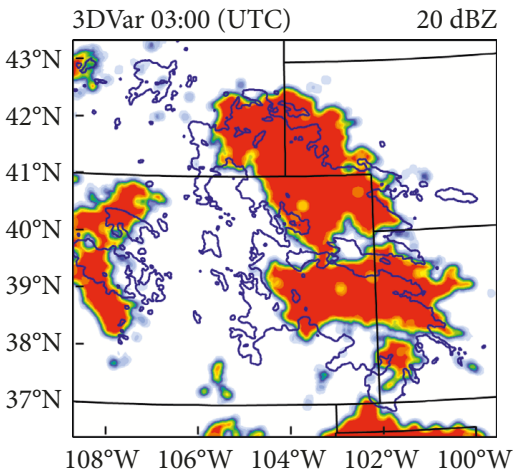

(e)

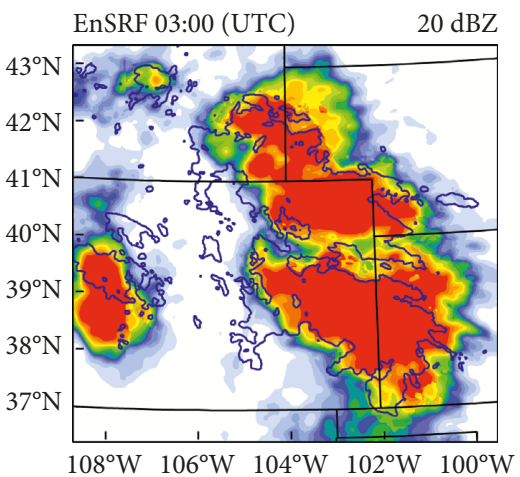

(h)

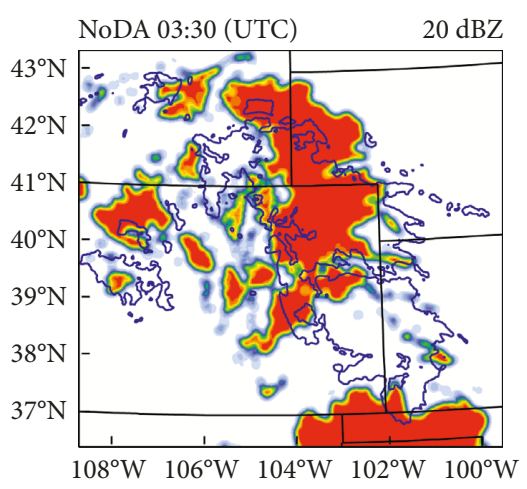

(c)

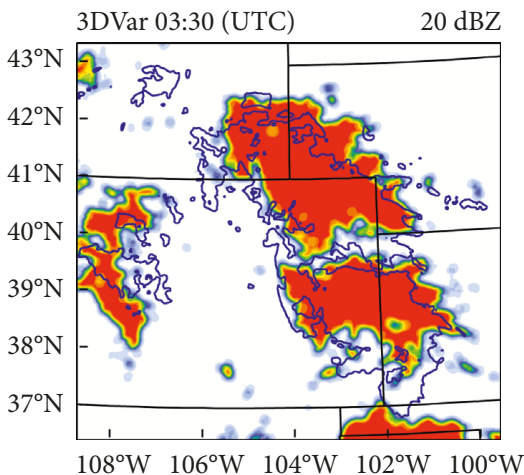

(f)

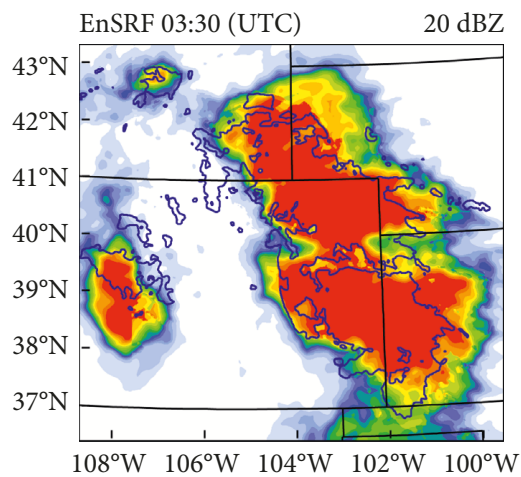

(i)

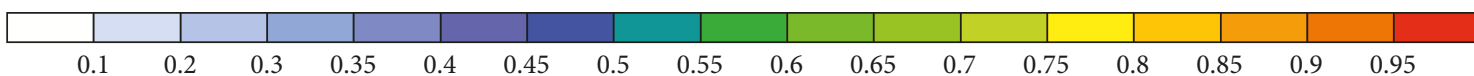

Figure 9: Neighborhood probabilities (NPs) of forecast radar reflectivity $>20 \mathrm{dBZ}$ at $0230 \mathrm{UTC}$ (a, d, g), $0300 \mathrm{UTC}$ (b, e, h), and $0330 \mathrm{UTC}$ $(c, f, i)$ on 30 July 2014 from the NoDA $(a-c)$, 3DVar $(d-f)$, and EnSRF ( $g-i)$ experiments. Regions of reflectivity $>20$ dBZ are outlined by the bold blue contour.

showed lower RMSIs than 3DVar during all analysis and forecast cycles, especially for the radial velocity at $t=10-30 \mathrm{~min}$. This suggests EnSRF had smaller analysis error compared with 3DVar. The spread of EnSRF was slightly lower than the RMSIs for radar reflectivity and radial velocity in the first $20 \mathrm{~min}$, suggesting underdispersion of the ensemble. Such underdispersion is a common problem in real radar DA at the convective scale $[12,34]$. However, the ensemble spreads of radar reflectivity and radial velocity were consistent with the RMSI values in the following cycles, indicating the forecast error was representative of the ensemble spread.
Figure 6 shows the analyzed composite radar reflectivity of the NoDA, 3DVar, and EnSRF experiments against observations at 0100 UTC 30 July 2014. The observed reflectivity at this time showed a strong MCS covering eastern Colorado and southeastern Wyoming, with a convective line at the Colorado-Wyoming border. Some weak convective cells also formed behind the MCS during its southeastward movement (Figure 6(a)). The NoDA experiment clearly overestimated a northward shift of the northern MCS, and it produced only disorganized convection in the southern MCS (Figure 6(b)). Conversely, both 3DVar and EnSRF successfully captured the distribution and location of the 


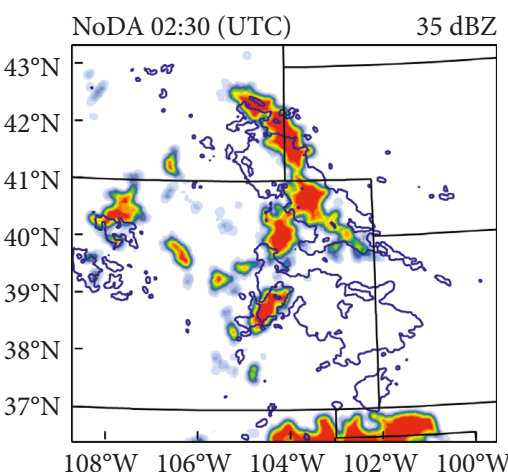

(a)

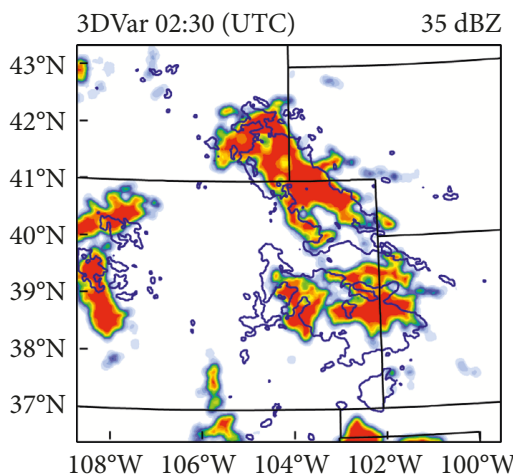

(d)

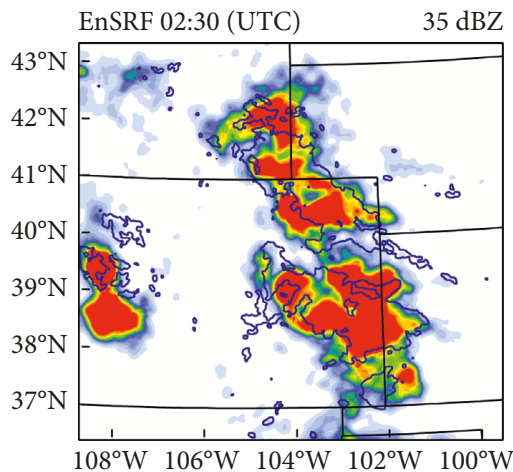

(g)

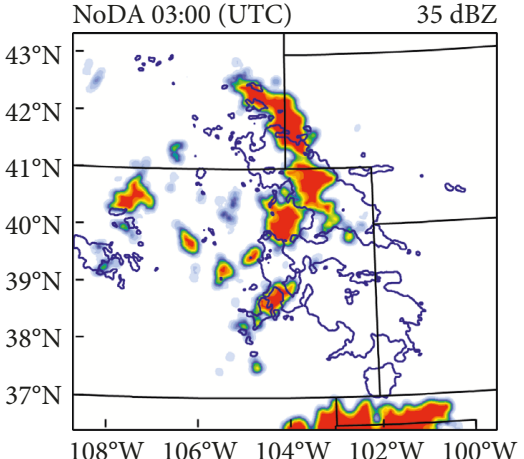

(b)

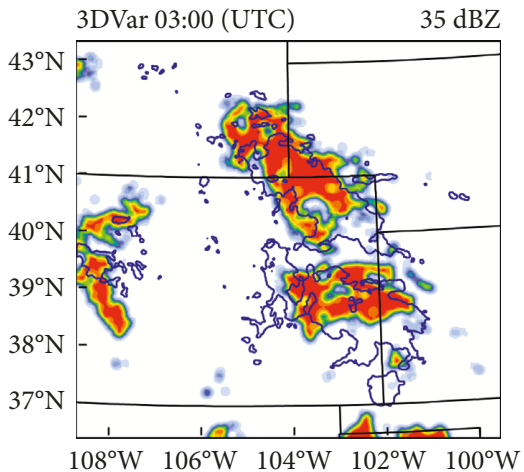

(e)

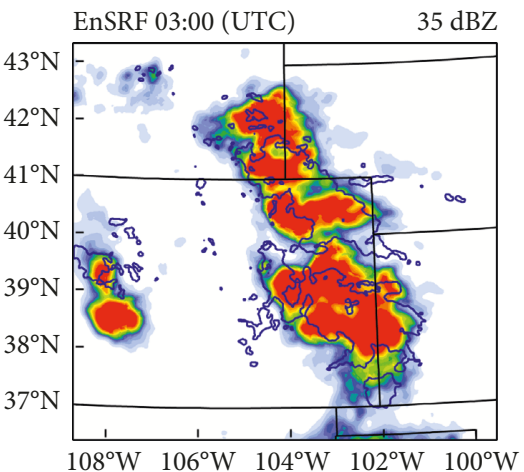

(h)

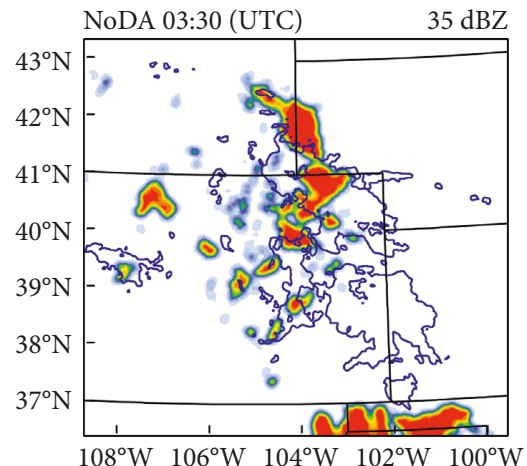

(c)

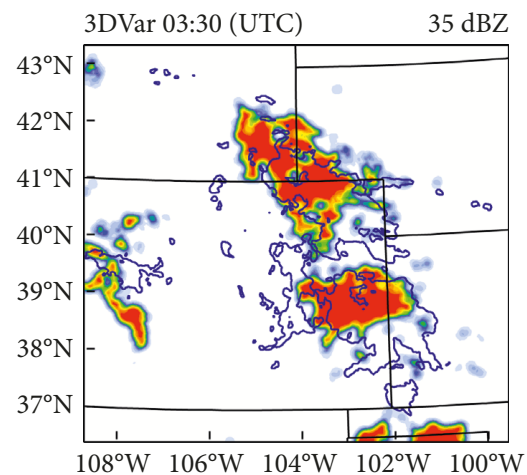

(f)

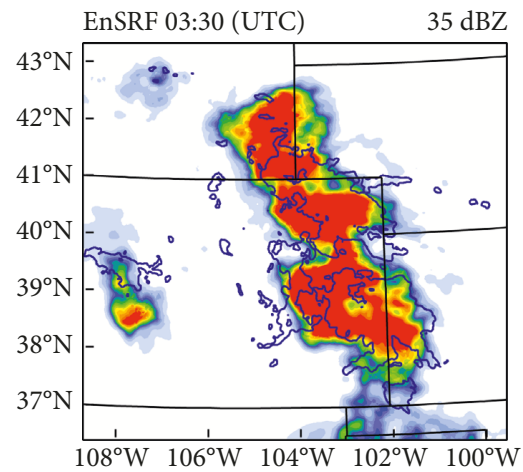

(i)

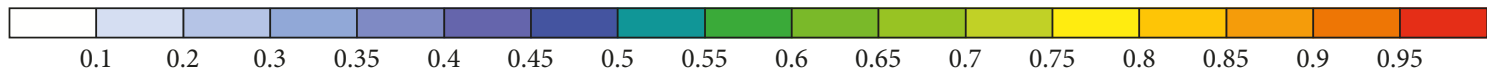

FIgURE 10: Neighborhood probabilities (NPs) of forecast radar reflectivity > $35 \mathrm{dBZ}$ at $0230 \mathrm{UTC}$ (a, d, g), $0300 \mathrm{UTC}$ (b, e, h), and 0330 UTC $(c, f, i)$ on 30 July 2014 from the NoDA $(a-c), 3 D V a r(d-f)$, and EnSRF ( $-\mathrm{i})$ experiments. Regions of reflectivity $>35$ dBZ are outlined by the bold blue contour.

MCS, reflecting the positive effect of radar DA. However, 3DVar overpredicted the intensity of convection with reflectivity of 30-40 dBZ (Figure 6(c)), while EnSRF reduced these overestimations, producing results much closer to the observations (Figure 6(d)). The surrounding weaker convection with reflectivity of $20-30 \mathrm{dBZ}$ was also analyzed better by EnSRF, particularly west of Kansas.

Surface temperature and wind field differences among the experiments at 0100 UTC were also pronounced (Figure 7). EnSRF presented the strongest cold pool with a broad area of low temperatures ranging from 10 to $18^{\circ} \mathrm{C}$ in the convective region, resulting from precipitation evaporation. Note that the solid black line represents the contour of reflectivity $>20 \mathrm{dBZ}$. The temperatures in the NoDA and 3DVar experiments were $12-20^{\circ} \mathrm{C}$ and $16-22^{\circ} \mathrm{C}$, respectively. The different features of the cold pool between the 3DVar and EnSRF experiments might be due to the lack of cross-variable correlations in the static BEC for hydrometeors in 3DVar [21]. Moreover, EnSRF adjusted the wind field better by producing the strongest wind, which plays an important role in maintaining convection.

4.2. Forecast Result. To assess the overall forecast performances quantitatively, four verification metrics were 


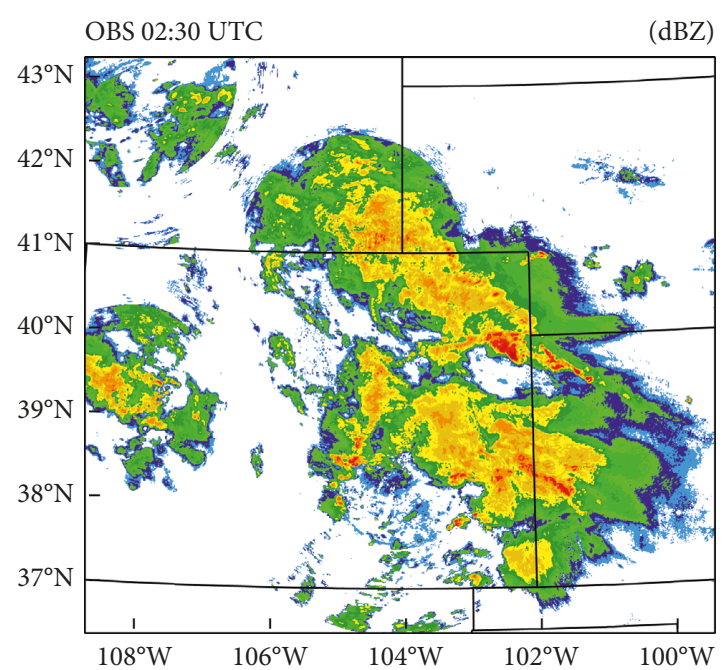

(a)

3DVar 02:30 UTC

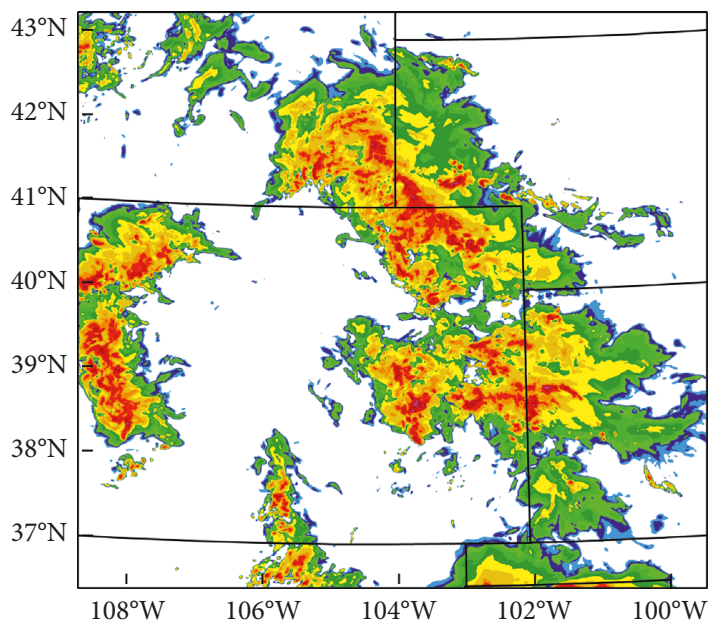

(c)
NoDA 02:30 UTC

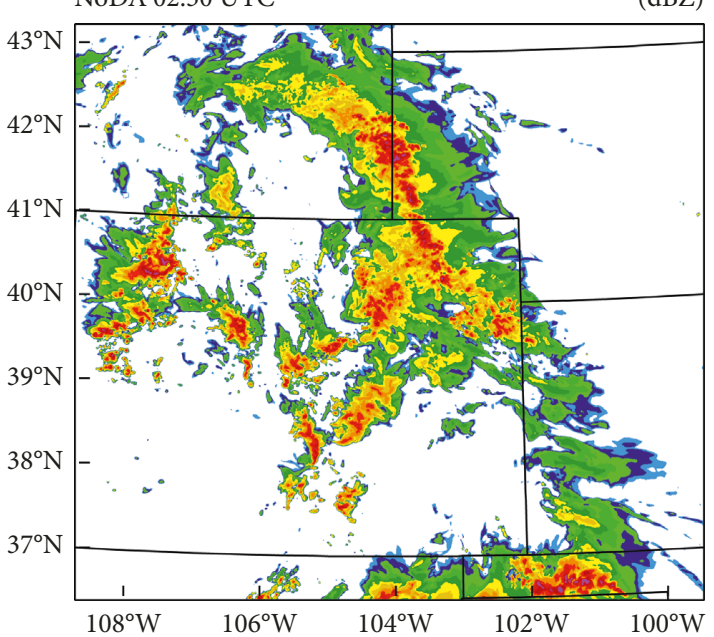

(b)

EnSRF 02:30 UTC

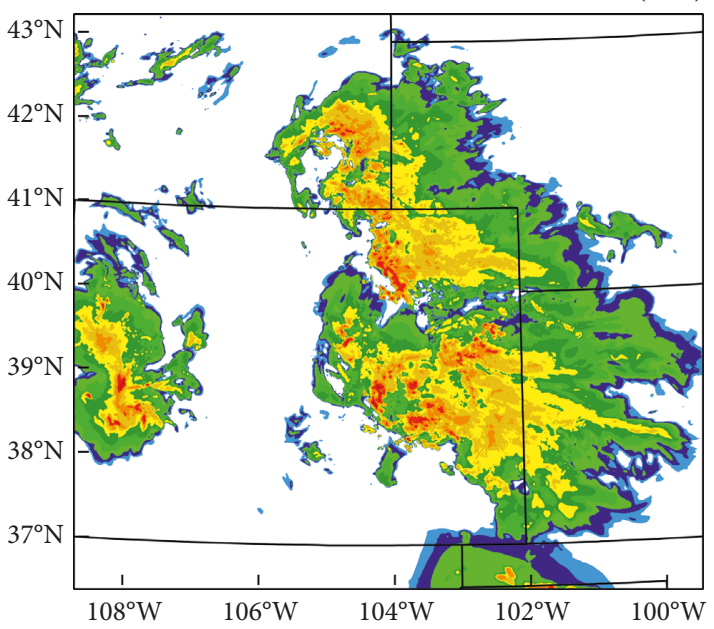

(d)

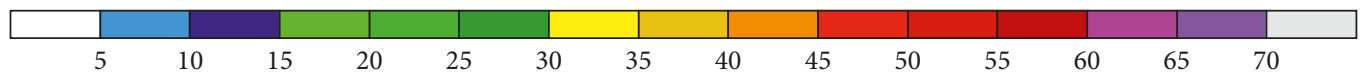

FiguRE 11: Composite reflectivity (unit: dBZ) of observations (a) and results from the NoDA (b), 3DVar (c), and EnSRF (d) experiments at 0230 UTC 30 July 2014.

adopted: the fractions skill score (FSS) [35], equitable threat score (ETS), BIAS, and false alarm ratio (FAR) [36]. The neighborhood-based FSS is defined as

$$
\mathrm{FSS}=1-\frac{(1 / N) \sum_{N}\left(p_{\mathrm{f}}-p_{\mathrm{o}}\right)^{2}}{(1 / N)\left(\sum_{N} p_{\mathrm{f}}^{2}+\sum_{N} p_{\mathrm{o}}^{2}\right)^{\prime}}
$$

where $p_{\mathrm{f}}$ and $p_{\mathrm{o}}$ are the forecast and observed fractional coverage of an elementary area by reflectivity or rainfall larger than a given threshold value, respectively, and $N$ represents the number of grid points in the verification domain. The FSS was calculated at each forecast time and each grid based on neighborhood sizes of $6 \mathrm{~km}$. It was then averaged over the domain every $10 \mathrm{~min}$.

The ETS calculates the fraction of observed events predicted correctly, while the BIAS and FAR represent the bias and false alarms of the reflectivity or precipitation forecast, respectively. They are defined as follows:

$$
\begin{aligned}
\text { ETS } & =\frac{a-c h}{a+c-c h}, \\
\text { BIAS } & =\frac{a+b}{a+c}, \\
\text { FAR } & =\frac{b}{a+b},
\end{aligned}
$$

where $a, b$, and $c$ are the numbers of hits, false alarms, and missing grids, respectively, and $c h$ is the number of hits expected through random chance. BIAS is greater (less) than 1.0 when the frequency of precipitation events, for a given threshold, is over-forecasted (under-forecasted). A perfect 
OBS 03:30 UTC

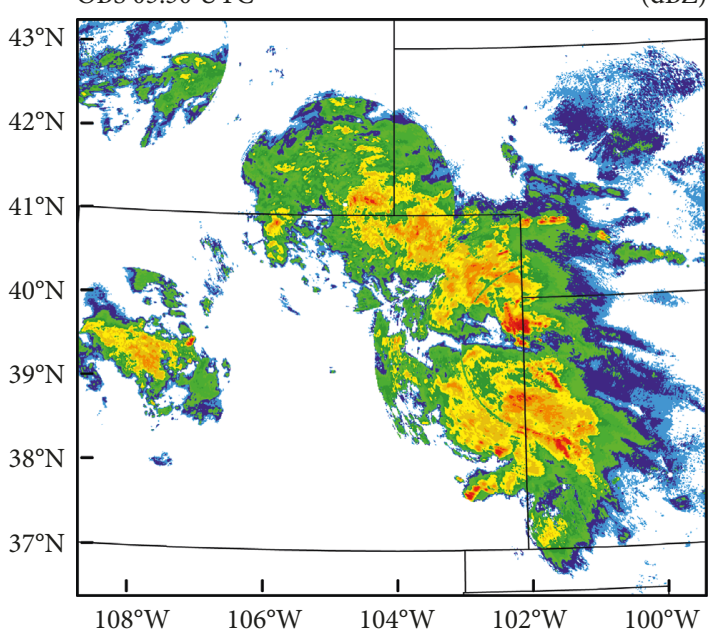

(a)

3DVar 03:30 UTC

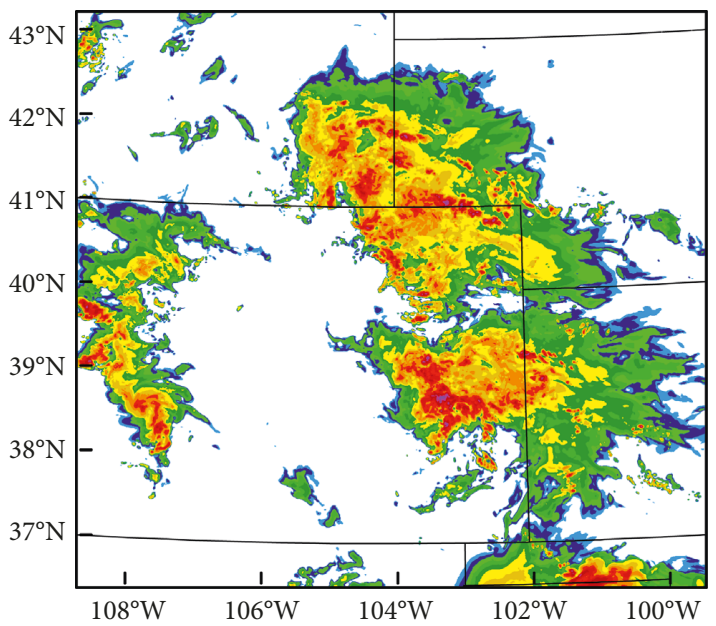

(c)
NoDA 03:30 UTC

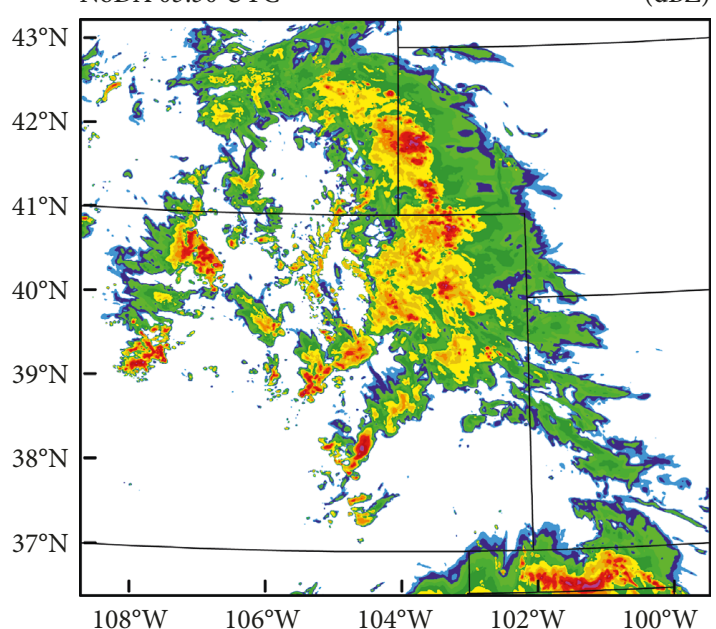

(b)

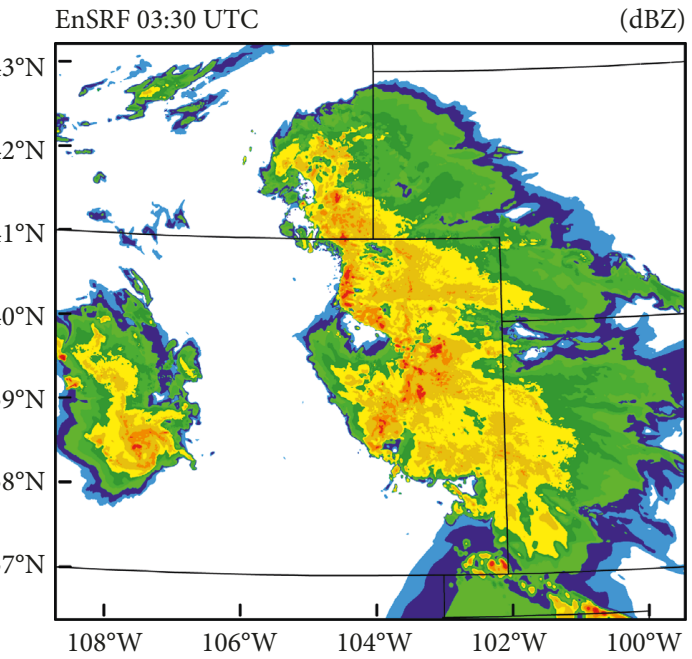

(d)

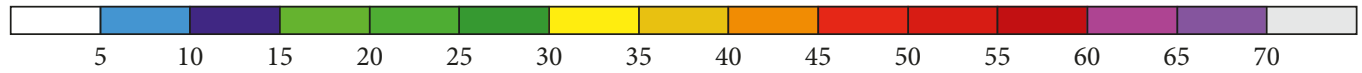

FIGURE 12: Composite reflectivity (unit: dBZ) of observations (a) and results from the NoDA (b), 3DVar (c), and EnSRF (d) experiments at 0330 UTC 30 July 2014.

forecast would be that the FSS, ETS, and BIAS are equal to 1.0 and FAR is equal to 0.0 .

The results of FSS, ETS, BIAS, and FAR for the forecast reflectivity from the NoDA, 3DVar, and EnSRF experiments are compared in Figure 8 for reflectivity thresholds of 5, 15, and $25 \mathrm{dBZ}$. NoDA had the lowest FSS and ETS for all thresholds during the entire forecast period. 3DVar had substantially higher FSS and ETS than NoDA, but the scores decreased more quickly than EnSRF for all thresholds, except for FSS during the first $10 \mathrm{~min}$ and during 160$200 \mathrm{~min}$ for $25 \mathrm{dBZ}$ (Figures 8(a)-8(f)). The BIAS shown in Figures $8(\mathrm{~g})-8(\mathrm{i})$ above or below 1 indicates reflectivity higher or lower than the observation. NoDA generally overestimated reflectivity above $5 \mathrm{dBZ}$, whereas it was reduced by 3DVar and EnSRF, particularly for the period 160-300 min. This was also true for $15 \mathrm{dBZ}$ at $t=100-300 \mathrm{~min}$ and for $25 \mathrm{dBZ}$ at $t=210-300 \mathrm{~min}$. It was also found that EnSRF reduced the overestimation by 3DVar to some extent for all thresholds. 3DVar and EnSRF also showed consistent improvements over NoDA in terms of smaller FAR, while EnSRF showed slightly lower FAR than 3DVar (Figures $8(\mathrm{~g})-8(\mathrm{l})$ ).

A neighborhood probability (NP; Schwartz et al. [37]) with a radius of $6 \mathrm{~km}$ was also calculated to verify the forecast radar reflectivity of the three experiments. Figure 9 shows the NP of reflectivity (>20 dBZ) at 0230, 0300, and 0330 UTC 30 July 2014 for the NoDA, 3DVar, and EnSRF experiments. The NP forecast of reflectivity ( $>20 \mathrm{dBZ}$ ) of NoDA, for which no radar data were assimilated, was less skillful than 3DVar and EnSRF. It produced a large area of probabilities of 0.0 in the southern MCS, indicating convection was not predicted (Figures 9(a)-9(c)). The reflectivity forecast was generally improved in the 3DVar experiment; however, it contained some underpredictions in the southern MCS (Figures 9(d)-9(f)). EnSRF improved the 


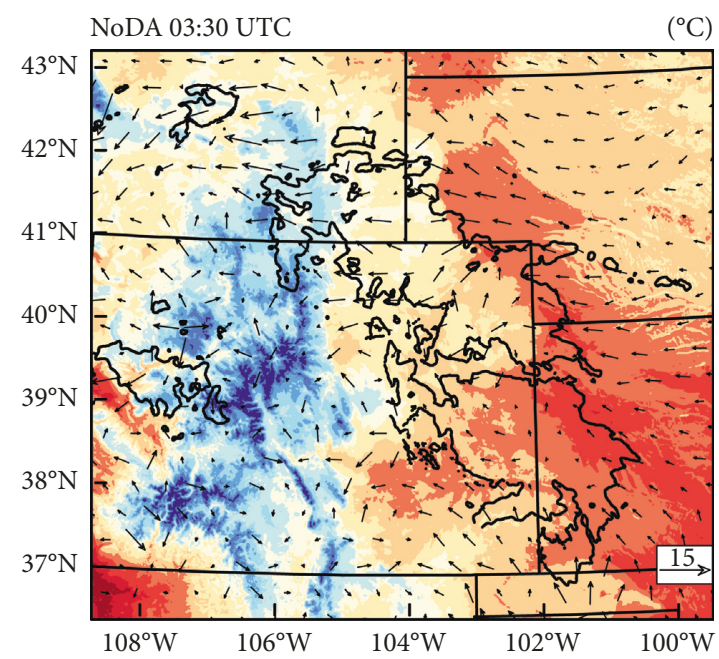

(a)

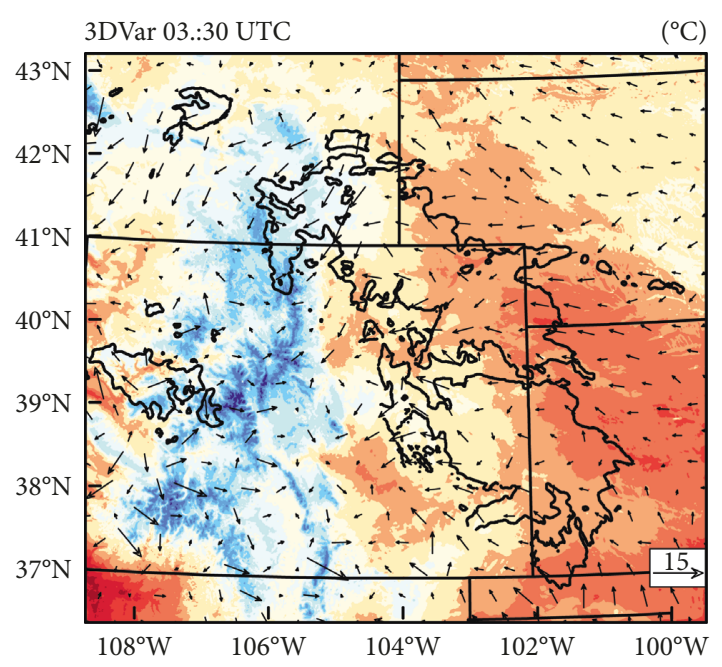

(b)

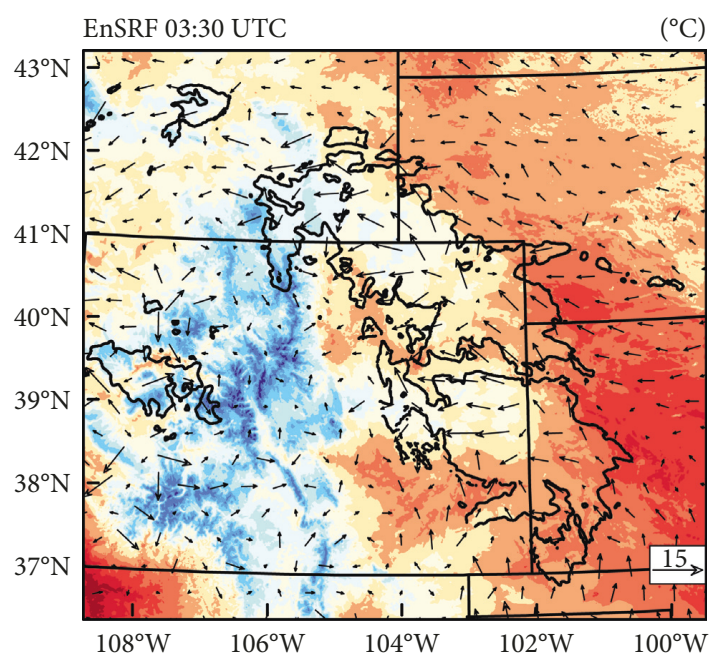

(c)

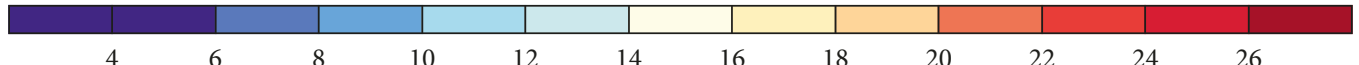

FIGURE 13: Surface temperature (unit: ${ }^{\circ} \mathrm{C}$ ) and wind (unit: $\mathrm{m} \cdot \mathrm{s}^{-1}$ ) from the NoDA (a), 3DVar (b), and EnSRF (c) experiments at $0330 \mathrm{UTC} 30$ July 2014. Solid black lines represent contours of observed reflectivity > $20 \mathrm{dBZ}$.

forecast of the entire MCS compared with the other two experiments. It predicted broad areas of high probability that closely matched the observed reflectivity $>20 \mathrm{dBZ}$ in terms of shape, extent, and position (Figures 9(g)-9(i)). In addition, the spurious convection along the Oklahoma panhandle, seen in both NoDA and 3DVar, was suppressed by EnSRF. The higher forecast skill of EnSRF was also evident for the threshold of $35 \mathrm{dBZ}$, which is associated with stronger convection (Figure 10). Although NoDA and 3DVar exhibited greater forecast error than for reflectivity $>20 \mathrm{dBZ}$, EnSRF had large overlap of high probabilities in the observed reflectivity ( $>35 \mathrm{dBZ}$ ) during the $1 \mathrm{~h}$ forecast, particularly at 0330 UTC.

Figure 11 shows the observed composite radar reflectivity as well as the forecast results for the NoDA, 3DVar, and EnSRF experiments at 0230 UTC 30 July 2014. By this time, the observed MCS had developed into a well-defined structure with an extensive area of stratiform precipitation. The convective center of the northern MCS in NoDA was highly overestimated with a northward displacement (Figure 11(b)). 3DVar produced a more realistic spatial pattern of the MCS, but the intensity of convection was overpredicted in the observed convective region (Figure 11(c)). EnSRF continued to present some improvements, including better representation of the stratiform precipitation and weaker reflectivity of 20-30 dBZ. The false storms produced over northwest Colorado by NoDA and $3 \mathrm{DV}$ ar were also corrected (Figure 11(d)). At 0330 UTC (Figure 12), NoDA (panel b) presented a weaker MCS with a reduced area of high reflectivity ( $>55 \mathrm{dBZ}$ ); however, the main system remained displaced to the north. 3DVar (panel c) successfully predicted two parts of the MCS, and the degree of overestimation was reduced to some extent compared with 0230 UTC. The moderate stratiform 

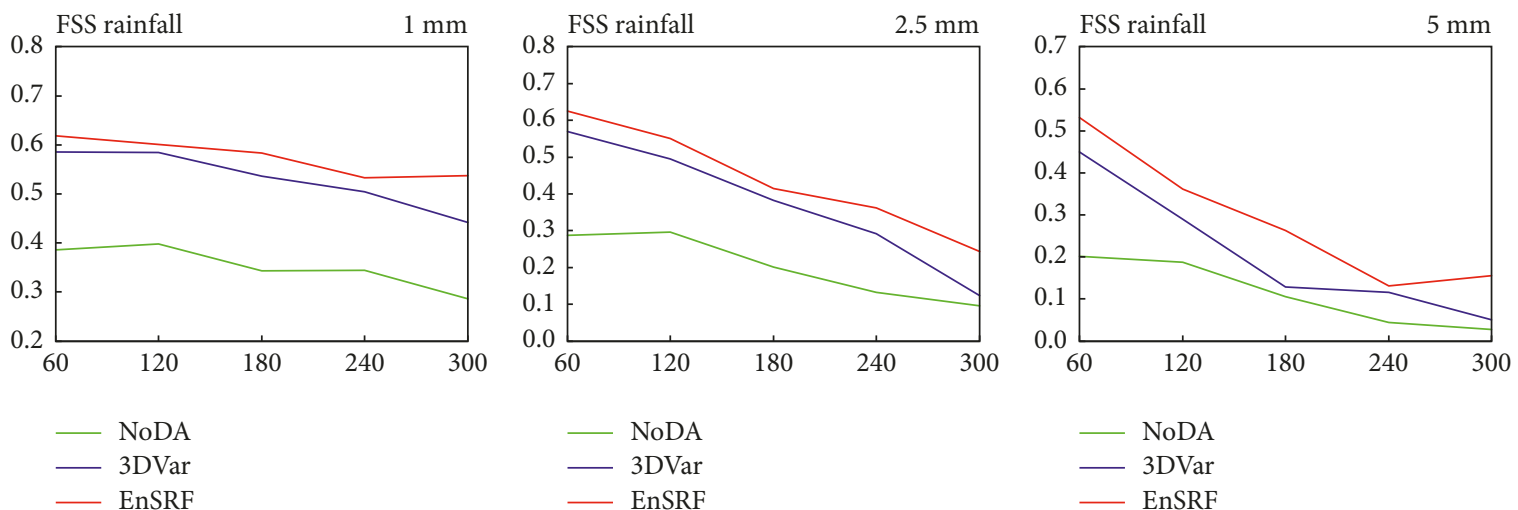

(a)

(b)

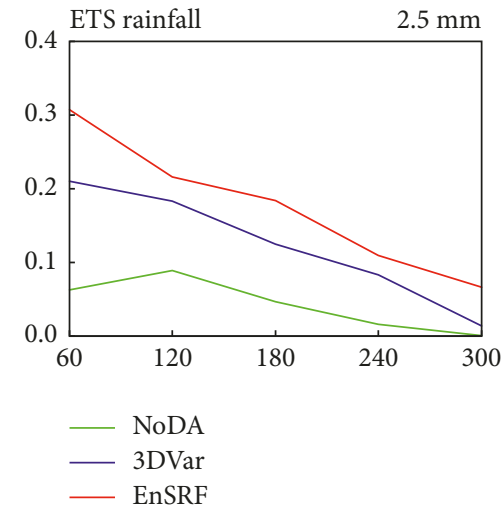

(e)

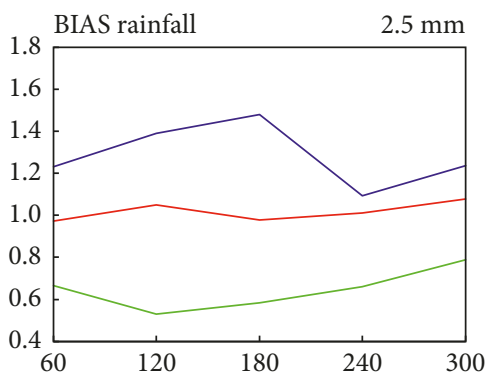

- NoDA

_ EnSRF

(h)

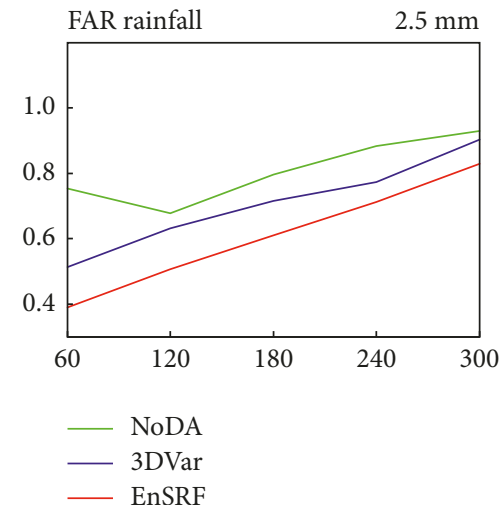

(k) (c)

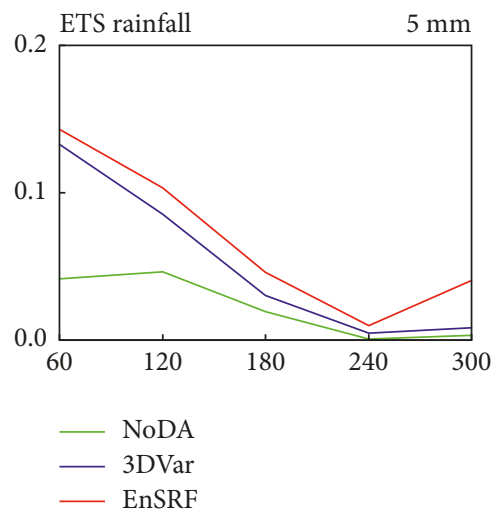

(f)

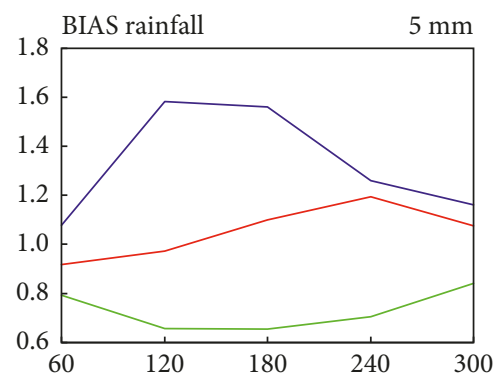

- NoDA

- 3DVar

_ EnSRF

(i)

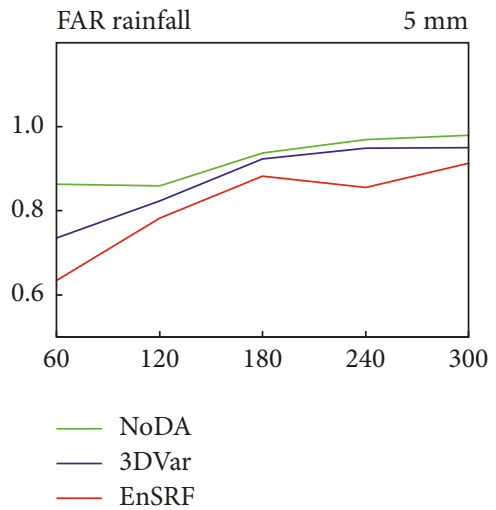

(l)

FIGURE 14: Fractions skill score (FSS) (a-c), equitable threat score (ETS) (d-f), BIAS (g-i), and false alarm ratio (FAR) (j-l) for precipitation thresholds of $1(\mathrm{a}, \mathrm{d}, \mathrm{g}, \mathrm{j}), 2.5(\mathrm{~b}, \mathrm{e}, \mathrm{h}, \mathrm{k})$, and $5 \mathrm{~mm}(1 \mathrm{~h})^{-1}(\mathrm{c}, \mathrm{f}, \mathrm{i}, \mathrm{l})$. 


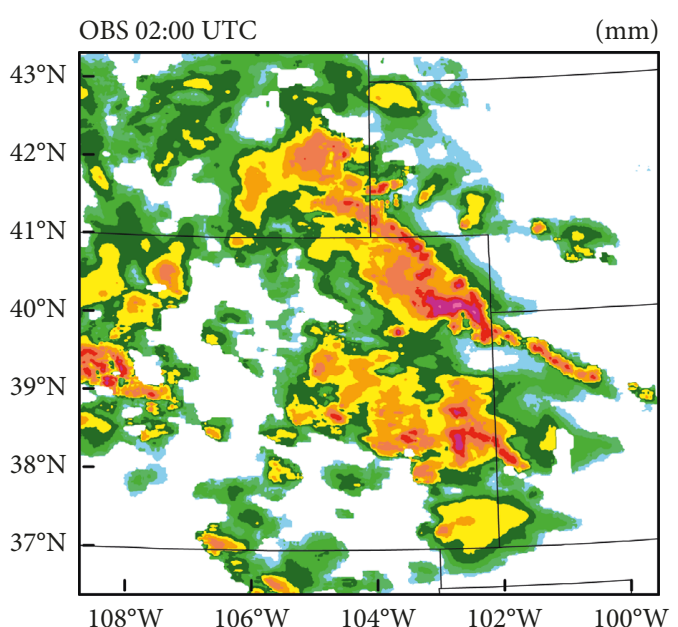

(a)

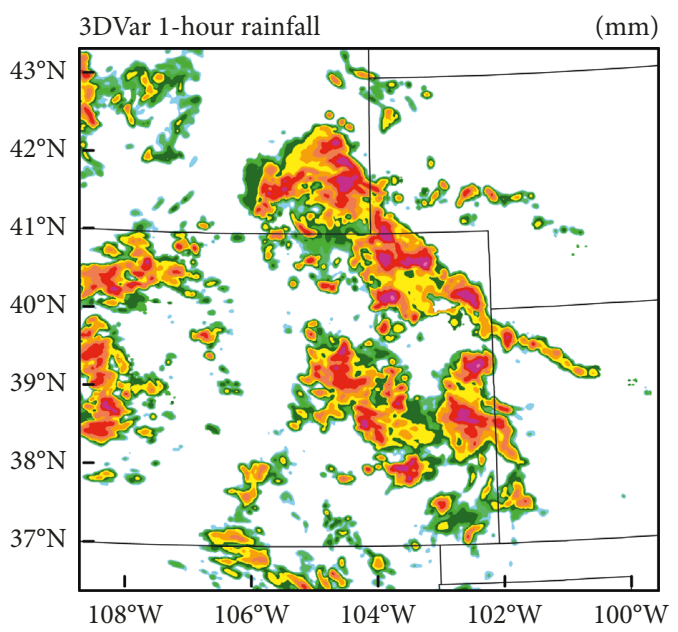

(c)

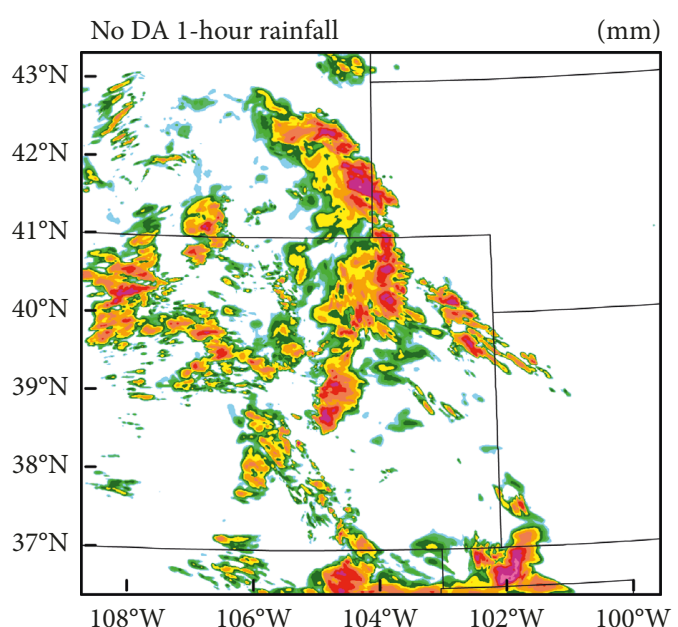

(b)

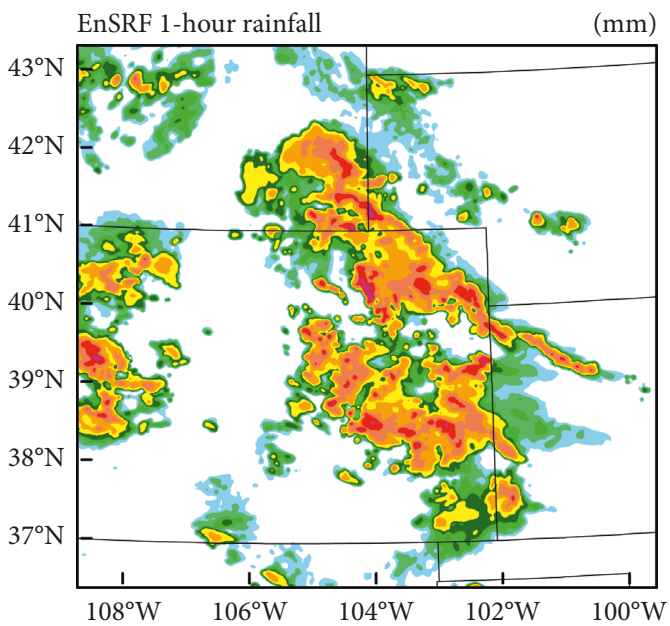

(d)

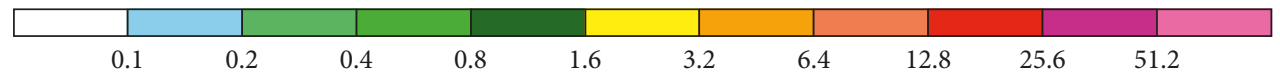

FIgure 15: One-hour accumulated precipitation (unit: mm) of observations (a) and results from the NoDA (b), 3DVar (c), and EnSRF (d) experiments starting at 0100 UTC 30 July 2014.

precipitation was simulated better by EnSRF (panel d), especially for the southern MCS, although with a larger areal coverage than observed. Unlike the analysis results, the cold pool in 3DVar was stronger than NoDA at this time, while EnSRF still had the strongest cold pool and a near-surface wind that helped maintain a more realistic MCS structure (Figure 13).

Precipitation is another important variable in convective weather. Figure 14 compares the FSS, ETS, BIAS, and FAR for the $5 \mathrm{~h}$ forecast from all three experiments. It can be seen that the assimilation of radar data in 3DVar (blue curve) and EnSRF (red curve) resulted in much higher FSS and ETS than NoDA for the thresholds of 1.0, 2.5, and $5.0 \mathrm{~mm}(1 \mathrm{~h})^{-1}$ during the entire forecast period. EnSRF showed relatively higher FSS and ETS than 3DVar, and the difference was larger in terms of FSS for the threshold of $5.0 \mathrm{~mm}(1 \mathrm{~h})^{-1}$ at $t=60-180 \mathrm{~min}$. EnSRF reduced the dry bias from 3DVar and NoDA for the threshold of $1.0 \mathrm{~mm}(1 \mathrm{~h})^{-1}$, and the BIAS of EnSRF (which was close to 1) was between 3DVar and
NoDA for the thresholds of 2.5 and $5.0 \mathrm{~mm}(1 \mathrm{~h})^{-1}$. NoDA presented the largest FAR, followed in descending order by 3DVar and EnSRF.

Figure 15 compares the forecast $1 \mathrm{~h}$ accumulated precipitation of the NoDA, 3DVar, and EnSRF experiments. 3DVar and EnSRF were noticeably superior to NoDA in terms of spatial pattern and amount but with different strengths. 3DVar overpredicted the MCS and it produced a larger area of heavy precipitation $(>25.6 \mathrm{~mm})$; however, it also missed some moderate $(1.6-12.8 \mathrm{~mm})$ and weaker precipitation $(0.2-1.6 \mathrm{~mm})$. In contrast, EnSRF predicted a broader area of precipitation than the other experiments, which agreed better with the observations, particularly for precipitation in the range $0.2-1.6 \mathrm{~mm}$. For the $3 \mathrm{~h}$ accumulated precipitation (Figure not shown), the observations produced a wider rainband with a larger area of heavy rain. 3DVar again produced too much heavy rain, whereas the EnSRF simulated precipitation had weaker amplitude but with wider coverage, as in the observations. 


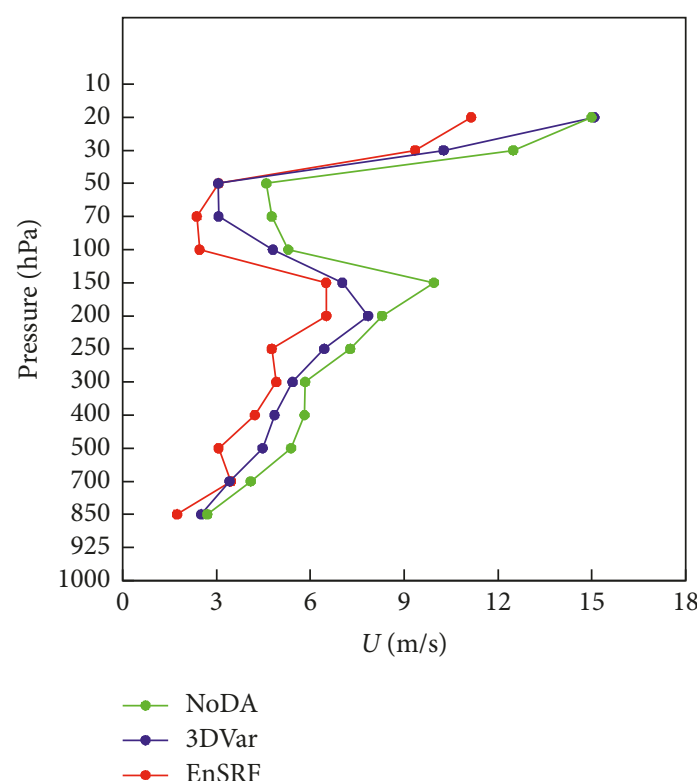

(a)

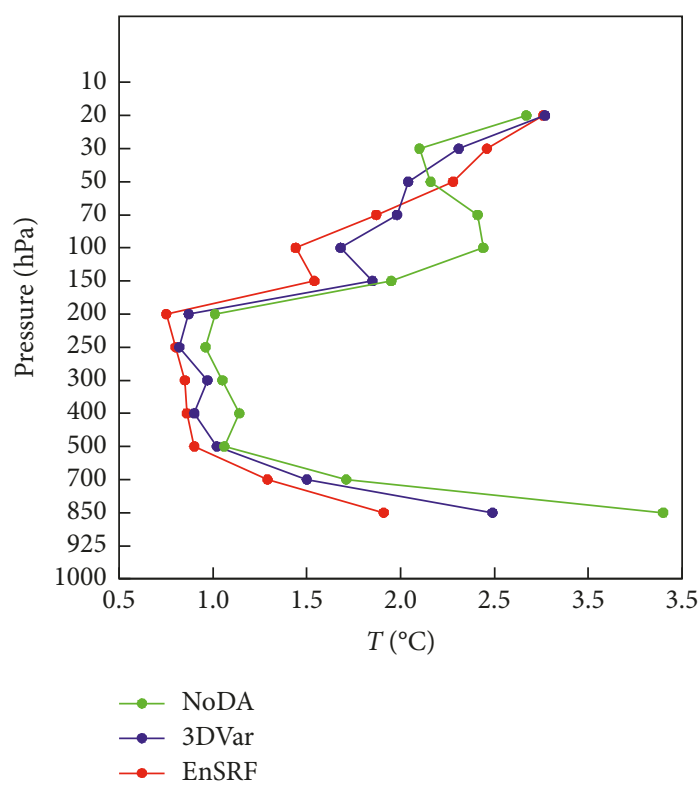

(c)

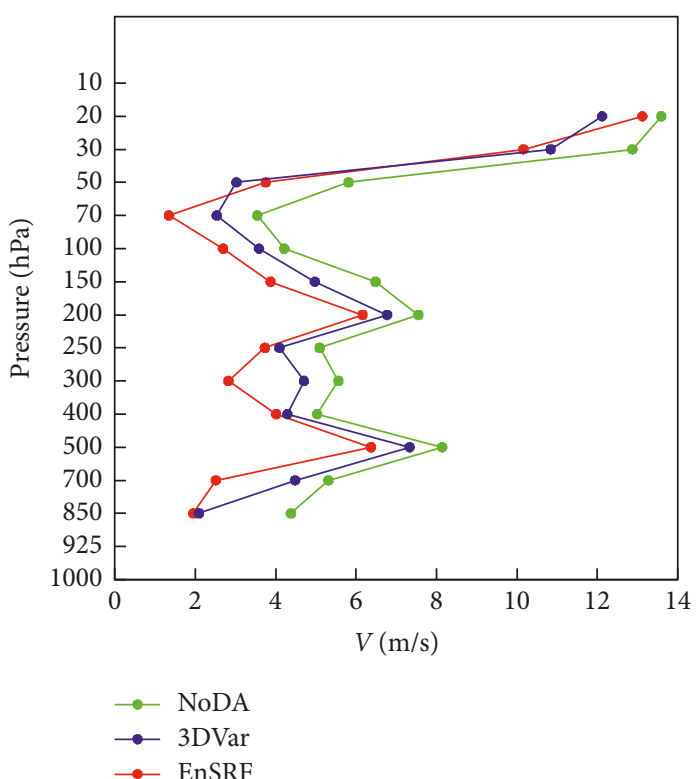

(b)

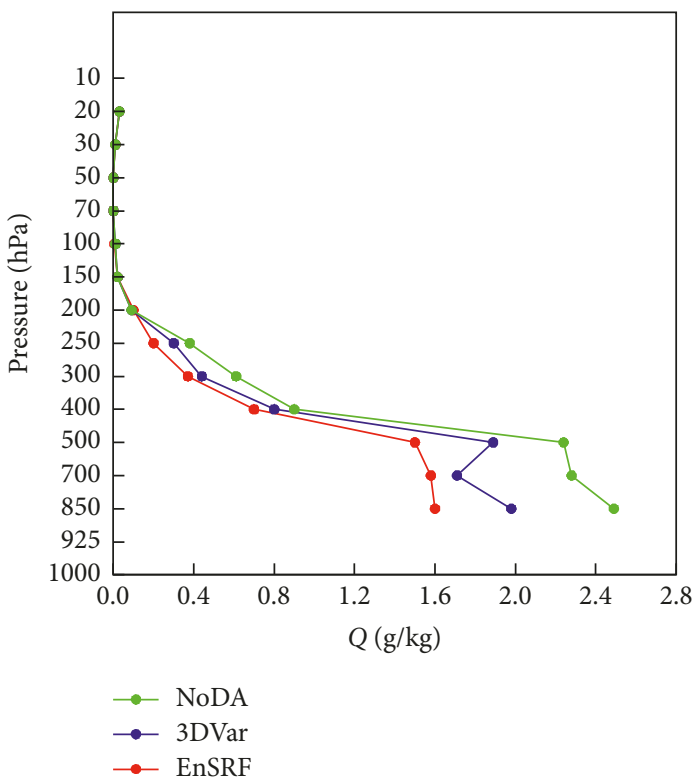

(d)

FIGURE 16: Vertical profiles of average root mean square errors (RMSEs) of forecasts against all radiosonde data in the $1 \mathrm{~km}$ domain for (a) the $u$ component (unit: $\mathrm{m} \mathrm{s}^{-1}$ ), (b) $v$ component (unit: $\mathrm{m} \cdot \mathrm{s}^{-1}$ ), (c) $T$ (unit: ${ }^{\circ} \mathrm{C}$ ), and (d) $Q$ (unit: $\mathrm{g} \cdot \mathrm{kg}^{-1}$ ) at $0300 \mathrm{UTC} 30 \mathrm{July} 2014$.

Figure 16 shows the vertical distribution of domainaveraged root mean square errors (RMSEs) of the horizontal wind components, temperature, and water vapor forecasts against all 10 radiosondes from the $1 \mathrm{~km}$ domain at 0300 UTC 30 July 2014. In comparison with NoDA and 3DVar, EnSRF (red curve) had slightly lower RMSEs for horizontal wind components and temperature below $70 \mathrm{hPa}$, and much smaller RMSEs for water vapor below $500 \mathrm{hPa}$. Figure 17 shows the RMSEs of horizontal wind components, temperature, and water vapor analyses against the data from all 781 surface METAR stations within the $1 \mathrm{~km}$ domain at 0300 UTC 30 July 2014. Evidently, EnSRF had the smallest
RMSEs, while the errors of NoDA were the largest and significantly reduced by $3 \mathrm{DV}$ ar and EnSRF for all variables.

\section{Summary}

In this study, the EnSRF and a recently developed indirect 3DVar method were used to assimilate radar data for an MCS that occurred over the Front Range of the Rocky Mountains in Colorado (USA) on 29-30 July 2014. Three experiments (NoDA, 3DVar, and EnSRF) were compared to investigate the impact of radar DA and different assimilation methods on both the analysis and the subsequent reflectivity 


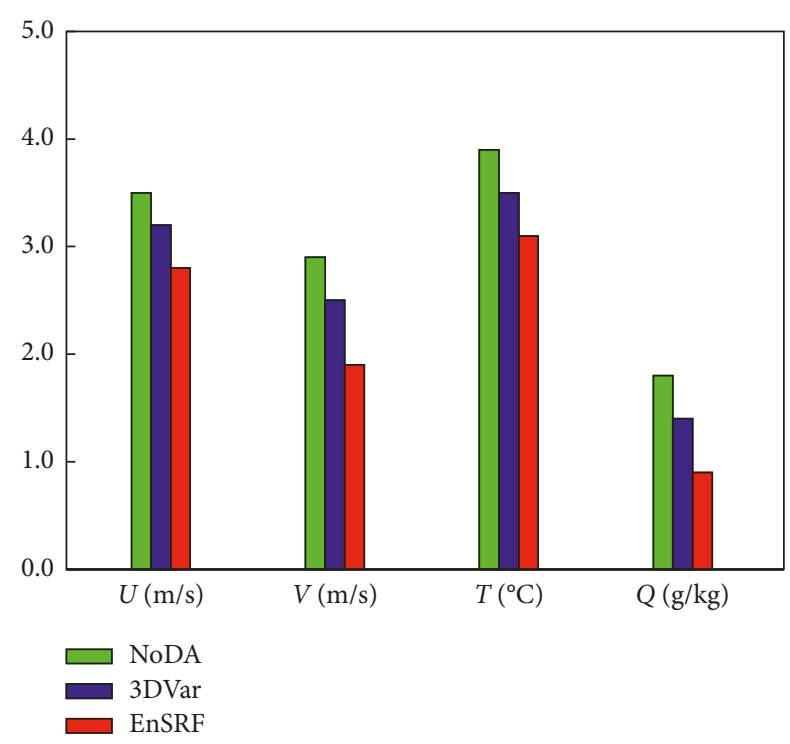

FIgURE 17: Average root mean square errors (RMSEs) of forecasts against all the data from METAR stations within the $1 \mathrm{~km}$ domain for the $u$ component (unit: $\mathrm{m} \cdot \mathrm{s}^{-1}$ ), $v$ component (unit: $\mathrm{m} \cdot \mathrm{s}^{-1}$ ), $T$ (unit: ${ }^{\circ} \mathrm{C}$ ), and $Q$ (unit: $\mathrm{g} \cdot \mathrm{kg}^{-1}$ ) at 0300 UTC 30 July 2014.

and precipitation forecasts. Both reflectivity and radial velocity data were assimilated from nine radars of the Weather Surveillance Radars-1988 Doppler network in the $3 \mathrm{~km}$ domain.

The analysis results showed that EnSRF reduced the RMSIs compared with 3DVar and that its ensemble spread and RMSI values were of comparable magnitude for both reflectivity and radial velocity in the analysis-forecast cycles. Assimilation of radar data resulted in considerable improvement of the analysis, and the analysis produced by EnSRF was more realistic than 3DVar in terms of intensity. EnSRF showed a stronger surface cold pool and wind outflow than 3DVar in the convective regions.

The positive impact of assimilating radar data was maintained for the forecast period, and EnSRF improved the quantitative reflectivity forecast skills measured by FSS, ETS, BIAS, and FAR over 3DVar. The NP of the reflectivity forecasts indicated that EnSRF produced the most skillful probabilistic forecast with high probabilities of the observed reflectivity with different thresholds that included moderate and strong convection. Although 3DVar improved the prediction of the extent of the MCS compared with NoDA, it was no better than EnSRF, especially for the southern MCS. The MCS structure was improved by both 3DVar and EnSRF in terms of location, intensity, and areal coverage, with EnSRF being the best. For precipitation, EnSRF also increased FSS and ETS and reduced FAR compared with NoDA and 3DVar, and it consistently produced the best BIAS for the different thresholds. The precipitation patterns and locations were represented well by 3DVar and EnSRF, although EnSRF reduced the overestimation of the heavy rainfall center compared with 3DVar. Verification against radiosonde sounding data in the $1 \mathrm{~km}$ domain suggested that the EnSRF reduced the RMSE of wind, temperature, and water vapor mixing ratio in comparison with $\mathrm{NoDA}$ and $3 \mathrm{DV}$ ar.
The present study demonstrated the encouraging results of EnSRF over 3DVar in MCS analysis and forecasting; however, further research involving additional cases and longer forecast periods will be necessary to reach conclusions that are more reliable. Further studies on radar DA using more advanced methods such as $4 \mathrm{DV}$ ar and hybrid DA are needed.

\section{Conflicts of Interest}

The authors declare no conflicts of interest.

\section{Acknowledgments}

This research was supported by the National Key Research and Development Program of China (Grant no. 2017YFC1502102) and the Research Innovation Program for College Graduates of Jiangsu Province (Grant no. KYLX_0829). The author Shibo Gao is supported by scholarship from the China Scholarship Council.

\section{References}

[1] Q. Xiao, Y.-H. Kuo, J. Sun et al., “Assimilation of Doppler radar observations with a regional 3DVAR system: impact of Doppler velocities on forecasts of a heavy rainfall case," Journal of Applied Meteorology, vol. 44, no. 6, pp. 768-788, 2005.

[2] Q. Xiao, Y. H. Kuo, J. Sun, W. C. Lee, D. M. Barker, and E. Lim, "An approach of radar reflectivity data assimilation and its assessment with the inland QPE of typhoon Rusa (2002) at landfall," Journal of Applied Meteorology and Climatology, vol. 46, no. 1, pp. 14-22, 2007.

[3] J. Gao and D. J. Stensrud, "Assimilation of reflectivity data in a convective-scale, cycled 3DVAR framework with hydrometeor classification," Journal of the Atmospheric Sciences, vol. 69, no. 3, pp. 1054-1065, 2012.

[4] H. Wang, J. Sun, S. Fan, and X. Y. Huang, "Indirect assimilation of radar reflectivity with WRF 3D-Var and its impact on prediction of four summertime convective events," Journal of Applied Meteorology and Climatology, vol. 52, no. 4, pp. 889-902, 2013.

[5] W. Tong, G. Li, J. Sun, X. Tang, and Y. Zhang, "Design strategies of an hourly update 3DVAR data assimilation system for improved convective forecasting," Weather and Forecasting, vol. 31, no. 5, pp. 1673-1695, 2016.

[6] E. P. Vendrasco, J. Sun, D. L. Herdies, and C. F. De Angelis, "Constraining a 3DVAR radar data assimilation system with large-scale analysis to improve short-range precipitation forecasts," Journal of Applied Meteorology and Climatology, vol. 55, no. 3, pp. 673-690, 2016.

[7] S. Gao, J. Sun, J. Min, Y. Zhang, and Z. Ying, "A scheme to assimilate "no rain" observations from Doppler radar," Weather and Forecasting, vol. 33, no. 1, pp. 71-88, 2018.

[8] C. Snyder and F. Zhang, "Assimilation of simulated Doppler radar observations with an ensemble Kalman filter," Monthly Weather Review, vol. 131, no. 8, pp. 1663-1677, 2003.

[9] F. Zhang, C. Snyder, and J. Sun, "Impacts of initial estimate and observation availability on convective-scale data assimilation with an ensemble Kalman filter," Monthly Weather Review, vol. 132, no. 5, pp. 1238-1253, 2004.

[10] M. Xue, M. Tong, and G. Zhang, "Simultaneous state estimation and attenuation correction for thunderstorms with 
radar data using an Ensemble Kalman Filter: tests with simulated data," Quarterly Journal of the Royal Meteorological Society, vol. 135, no. 643, pp. 1409-1423, 2009.

[11] M. Xue, M. Tong, and K. K. Droegemeier, “An OSSE framework based on the ensemble square root Kalman filter for evaluating the impact of data from radar networks on thunderstorm analysis and forecasting," Journal of Atmospheric and Oceanic Technology, vol. 23, no. 1, pp. 46-66, 2006.

[12] F. Zhang, Y. Weng, J. F. Gamache, and F. D. Marks, "Performance of convection-permitting hurricane initialization and prediction during 2008-2010 with ensemble data assimilation of inner-core airborne Doppler radar observations," Geophysical Research Letters, vol. 38, no. 15, p. L15810, 2011.

[13] T. A. Jones, K. Knopfmeier, D. Wheatley, G. Creager, P. Minnis, and R. Palikonda, "Storm-scale data assimilation and ensemble forecasting with the nssl experimental warn-onforecast system. Part II: combined radar and satellite data experiments," Weather and Forecasting, vol. 31, no. 1, pp. 297-327, 2016.

[14] M. Xue, Y. Jung, and G. Zhang, "State estimation of convective storms with a two-moment microphysics scheme and an ensemble Kalman filter: experiments with simulated radar data," Quarterly Journal of the Royal Meteorological Society, vol. 136, no. 648, pp. 685-700, 2010.

[15] N. Snook, Y. Jung, J. Brotzge, B. Putnam, and M. Xue, "Prediction and ensemble forecast verification of hail in the supercell storms of 20 May 2013," Weather and Forecasting, vol. 31, no. 3, pp. 811-825, 2016.

[16] D. T. Dawson, L. J. Wicker, E. R. Mansell, Y. Jung, and M. Xue, "Low-level polarimetric radar signatures in EnKF analyses and forecasts of the May 8, 2003 Oklahoma City tornadic supercell: impact of multimoment microphysics and comparisons with observation," Advances in Meteorology vol. 2013, Article ID 818394, 13 pages, 2013.

[17] Z. Pu, H. Zhang, and J. Anderson, "Ensemble Kalman filter assimilation of near-surface observations over complex terrain: comparison with 3DVAR for short-range forecasts," Tellus, Series A: Dynamic Meteorology and Oceanography, vol. 65, no. 1, p. 19620, 2013.

[18] J. S. Whitaker, G. P. Compo, and J.-N. Thépaut, "A comparison of variational and ensemble-based data assimilation systems for reanalysis of sparse observations," Monthly Weather Review, vol. 137, no. 6, pp. 1991-1999, 2009.

[19] X. Wang, "Application of the WRF hybrid ETKF-3DVAR data assimilation system for hurricane track forecasts," Weather and Forecasting, vol. 26, no. 6, pp. 868-884, 2011.

[20] Z. Meng and F. Zhang, "Limited-area ensemble-based data assimilation," Monthly Weather Review, vol. 139, no. 7, pp. 2025-2045, 2011.

[21] A. Johnson, X. Wang, J. R. Carley, L. J. Wicker, and C. Karstens, "A comparison of multiscale GSI-based EnKF and 3DVardata assimilation using radar and conventional observations for midlatitude convective-scale precipitation forecasts," Monthly Weather Review, vol. 143, no. 8, pp. 3087-3108, 2015.

[22] J. S. Whitaker and T. M. Hamill, "Ensemble data assimilation without perturbed observations," Monthly Weather Review, vol. 130, no. 7, pp. 1913-1924, 2002.

[23] J. L. Anderson, "An adaptive covariance inflation error correction algorithm for ensemble filters," Tellus, Series A: Dynamic Meteorology and Oceanography, vol. 59, no. 2, pp. 210-224, 2007.

[24] J. S. Kain and J. M. Fritsch, "A one-dimensional entraining/ detraining plume model and its application in convective parameterization," Journal of the Atmospheric Sciences, vol. 47, no. 23, pp. 2784-2802, 1990.

[25] G. Thompson, R. M. Rasmussen, and K. Manning, "Explicit forecasts of winter precipitation using an improved bulk microphysics scheme. Part I: description and sensitivity analysis," Monthly Weather Review, vol. 132, no. 2, pp. 519$542,2004$.

[26] Z. I. Janjić, "The step-mountain Eta coordinate model: further developments of the convection, viscous sublayer, and turbulence closure schemes," Monthly Weather Review, vol. 122, no. 5, pp. 927-945, 1994.

[27] F. Chen and J. Dudhia, "Coupling an advanced land surface-hydrology model with the Penn State-NCAR MM5 modeling system. Part I: model implementation and sensitivity," Monthly Weather Review, vol. 129, no. 4, pp. 569-585, 2001.

[28] M. J. Iacono, J. S. Delamere, E. J. Mlawer, M. W. Shephard, S. A. Clough, and W. D. Collins, "Radiative forcing by longlived greenhouse gases: calculations with the AER radiative transfer models," Journal of Geophysical Research Atmospheres, vol. 113, no. D13, 2008.

[29] K. Brewster, M. Hu, M. Xue, and J. Gao, "Efficient assimilation of radar data at high resolution for short range numerical weather prediction," in Proceedings of World Weather Research Program Symposium and Nowcasting and Very ShortRange Forecasting, pp. 1-14, Whistler, BC, Canada, August 2005.

[30] J. Zhang, K. Howard, C. Langston et al., "Multi-radar multisensor (MRMS) quantitative precipitation estimation: initial operating capabilities," Bulletin of the American Meteorological Society, vol. 97, no. 4, pp. 621-638, 2016.

[31] D. F. Parrish and J. C. Derber, "the national meteorological center's spectral statistical-interpolation analysis system," Monthly Weather Review, vol. 120, no. 8, pp. 1747-1763, 1992.

[32] D. M. Barker, "Southern high-latitude ensemble data assimilation in the Antarctic mesoscale prediction system," Monthly Weather Review, vol. 133, no. 12, pp. 3431-3449, 2005.

[33] D. C. Dowell and L. J. Wicker, "Additive noise for storm-scale ensemble data assimilation," Journal of Atmospheric and Oceanic Technology, vol. 26, no. 5, pp. 911-927, 2009.

[34] D. M. Wheatley, K. H. Knopfmeier, T. A. Jones, and G. J. Creager, "Storm-scale data assimilation and ensemble forecasting with the NSSL experimental warn-on-forecast system. Part I: radar data experiments," Weather and Forecasting, vol. 30, no. 6, pp. 272-294, 2015.

[35] M. Mittermaier and N. Roberts, "Intercomparison of spatial forecast verification methods: identifying skillful spatial scales using the fractions skill score," Weather and Forecasting, vol. 25, no. 1, pp. 343-354, 2010.

[36] F. Mashingia, F. Mtalo, and M. Bruen, "Validation of remotely sensed rainfall over major climatic regions in northeast Tanzania," Physics and Chemistry of the Earth, vol. 67-69, pp. 55-63, 2014.

[37] C. S. Schwartz, J. S. Kain, S. J. Weiss et al., “Toward improved convection-allowing ensembles: Model physics sensitivities and optimizing probabilistic guidance with small ensemble membership," Weather and Forecasting, vol. 25, no. 1, pp. $263-280,2010$. 

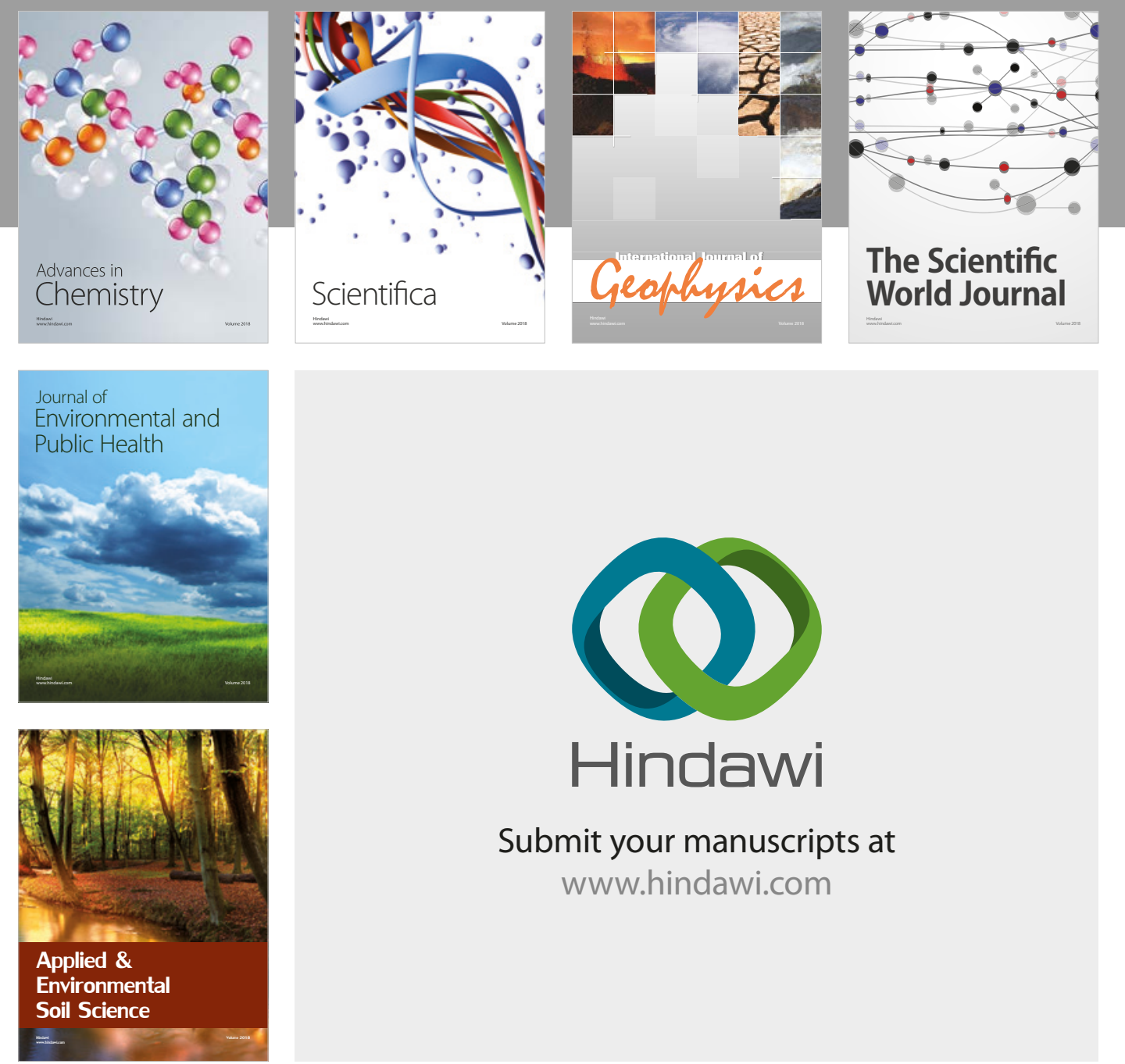

The Scientific

\section{World Journal}
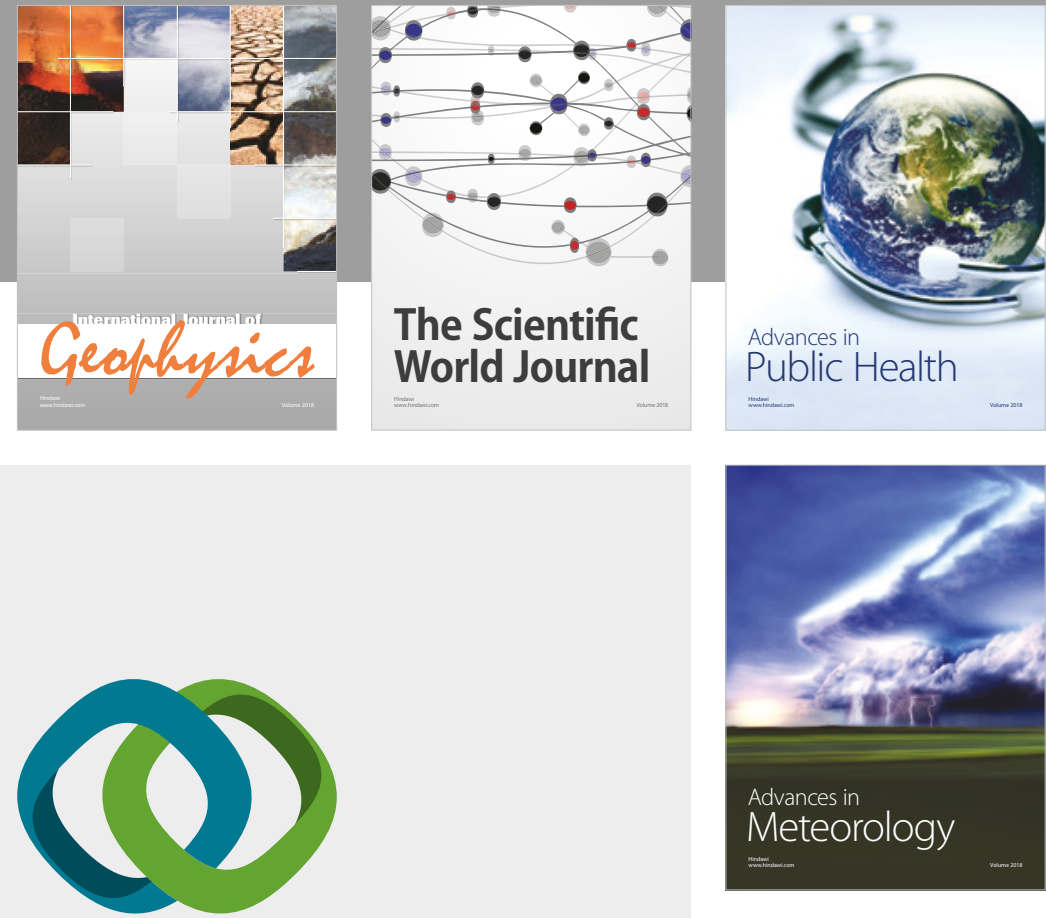

Advan

Public Health

\section{Hindawi}

Submit your manuscripts at

www.hindawi.com
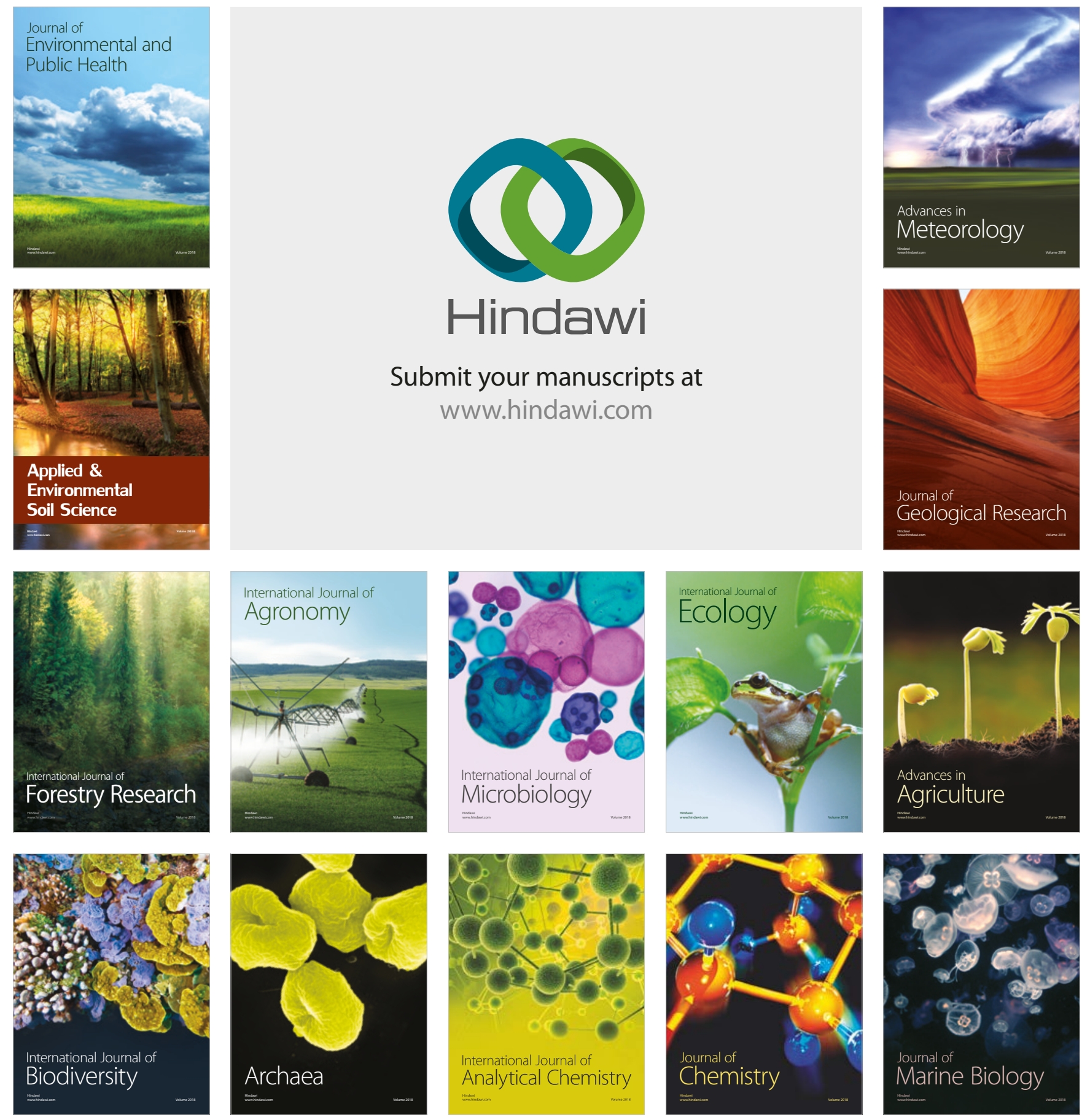